
\title{
25 Research Soure \\ OsRuvBL1a DNA Helicase Boost Salinity and Drought Tolerance in Transgenic Indica Rice Raised by In-Planta Transformation
}

\section{Shabnam K Saifi}

ICGEB New Delhi: International Centre For Genetic Engineering and Biotechnology New Delhi

\section{Nishat Passricha}

ICGEB New Delhi: International Centre For Genetic Engineering and Biotechnology New Delhi

\section{Renu Tuteja}

ICGEB New Delhi: International Centre For Genetic Engineering and Biotechnology New Delhi

\section{Manoj Nath}

Directorate of Mushroom Research

\section{Sarvajeet Singh Gill}

MDU: Maharshi Dayanand University Rohtak

Narendra Tuteja ( $\triangle$ ntuteja@amity.edu )

Amity University Uttar Pradesh https://orcid.org/0000-0002-0693-5136

\section{Research Article}

Keywords: Abiotic stress, Agrobacterium, Helicase, in-planta, Rice, RuvBL1

Posted Date: May 18th, 2021

DOI: https://doi.org/10.21203/rs.3.rs-405060/v1

License: (c) (1) This work is licensed under a Creative Commons Attribution 4.0 International License.

Read Full License 


\section{Abstract}

RuvBL, is a member of SF6 superfamily of helicases and is conserved among the various model systems. Recently rice homolog of RuvBL has been biochemically characterized for its ATPase and DNA helicase activities, however its involvement in stress is not been studied yet. This study reports the detailed functional characterization of RuvBL homolog of Oryza sativa, under abiotic stress through transgenic approach. An improved Agrobacterium-mediated in-planta transformation method was developed in indica rice to generate the transgenic lines and study was focused on optimization of factors to achieve maximum transformation efficiency. Overexpressing OsRuvBL 1a transgenics showed enhanced tolerance under in vivo salinity stress as compared to WT plants. The physiological and biochemical analysis of the OsRuvBL 1a transgenic lines showed better performance under salinity and drought stresses. Several stress responsive interacting partners of OsRuvBL1a were identified using $\mathrm{Y} 2 \mathrm{H}$ method. Working mechanism for boosting the stress tolerance by OsRuvBL1a has been proposed in this study. This integration of OSRuvBL 1a gene in rice genome using in-planta transformation method helped us to achieve the abiotic stress tolerant smart crop. This study is the first direct evidence to show the novel function of RuvBL in boosting abiotic stress tolerance in plants.

\section{Key Message:}

RuvB protein of helicase family has shown role in abiotic stress tolerance and for characterization rice transgenic plant were raised by newly developed in-vivo seed transformation protocol.

\section{Introduction:}

Global climate change and population explosion make it compulsory to utilize the full genetic potential of plants for feeding the world population (Edgerton 2009; Godfray et al. 2010; Passricha et al. 2014; Passricha et al. 2020). Abiotic stresses adversely affect the plants growth at various levels (Gao and Lan 2016; Passricha et al. 2019b). To overcome these adverse effects, stress tolerant varieties need to be developed. Genetic engineering has enlightened the path to use proteins, which are responsible for providing tolerance, and helicases such as MCM6, XPB2, PDH45, p68, OsSUV3 and OsBAT1 have been reported to impart abiotic stress tolerance (Dang et al. 2011; Liu et al. 2020; Passricha et al. 2019a; Shivakumara et al. 2017; Tuteja et al. 2014). Helicases exhibit ATPase activity and provide energy for unwinding the duplex nucleic acids (Abrahao et al. 2021; Lupas and Martin 2002) and thus are involved in various cellular functions (Nath et al. 2015; Saifi et al. 2019; Tuteja et al. 2015). Helicases are functionally coupled to the additional components of the macromolecular machines and participate in diverse biological processes. Helicases have 6 superfamilies, SF1 through SF6. Among these, SF6 comprises members of AAA+ (ATPases Associated with various cellular Activities) family, which exhibit nucleic acid unwinding activity (Abrahao et al. 2021; Saifi et al. 2018; Saifi et al. 2019; Singleton et al. 2007). Sequence analysis of AAA + superfamily shows its conservation among prokaryotes and eukaryotes. An important and highly conserved member of this AAA + superfamily is RuvB (Snider et al. 2008). 
RuvB is a highly conserved protein involved in various cellular functions such as cell cycle regulation (Ahmad and Tuteja 2012), mitotic assembly (Morrison and Shen 2009; Sigala et al. 2005), transcriptional regulation of gene expression (Jonsson et al. 2001; Wood et al. 2000) and biogenesis and assembly of snoRNPs (small nucleolar ribonucleoproteins) for the generation of pre-rRNA (Zhao et al. 2008). It is a widely studied protein in other systems but is scarcely studied in plants with few reports on Arabidopsis (Holt et al. 2002; Schorova et al. 2019) and rice (Wang et al. 2011). In this study, we report the functional characterization of OsRuvBL1a, a rice homolog of RuvB1 which exhibits nucleic acid independent ATPase and nucleic acid unwinding activity (Saifi et al. 2018).

Over-expression of OsRuvBL1a encoding gene in rice plant has been used for the functional validation of the gene. Several methods have been reported for Agrobacterium-mediated transformation of the Indica rice such as tissue culture (Sahoo and Tuteja 2012), seed-piercing (Lin et al. 2009; Supartana et al. 2005), vacuum infiltration (Lin et al. 2009), floral-drip and floral-drop method (Ratanasut et al. 2017). All these methods have limitations of being laborious, having somaclonal variations, genotype-dependent, expensive and time-consuming which render indica rice transformation a tough process (Lin et al. 2009; Nishimura et al. 2005; Ratanasut et al. 2017). Some alternative fast and advantageous transformation method is needed to develop transgenics of rice (Dong et al. 2001). Callus regeneration method is the most widely used method for the rice transformation. However, the method is also beset with limitations such as, time consumption, somaclonal variations (Fukui 1983), genotype specificity and epigenetic changes (Smulders and de Klerk 2010) that reduce the rice transformation efficiency. This further reinforces the need for the development of a new transformation method (Hansen and Wright 1999).

In-planta seed transformation of rice is a new emerging and efficient method that overcomes the limitations of callus method (Bent 2000). In-planta rice transformation through seed was first attempted by Supartana et al. (2005) by piercing the pre-soaked seed embryo using Agrobacterium tumefaciens dipped needle (Supartana et al. 2005). Although this method opened the avenues for new improved way for rice transformation, however, the method need to be improvised to make it more prompt and easy to carry out. We, in the present study, have therefore attempted to improvise the in-planta transformation protocol with improved efficiency. Moreover, the improvised method is faster and easy to perform than the previously reported in-planta transformation methods (Lin et al. 2009; Ratanasut et al. 2017; Supartana et al. 2005). Further, the study involved the detailed analysis of OsRuvBL1a overexpressing transgenic lines produced using this new improved method. The recombinant OsRuvBL1a overexpressing lines seemed to be more tolerant to salinity and drought stress as surmised by reactive oxygen species (ROS) level, membrane stability and chlorophyll retention. Further, Yeast two-hybrid analysis was also carried out to predict the interacting partners of the OsRuvBL1a that may play a part in imparting the stress tolerance to rice.

\section{Experimental Procedure:}

OsRuvBL 1a gene selection 
Preliminary studies involving stress responsive expression level analysis was performed for OsRuvBL 1a gene for the selection of candidate RuvBL gene from RuvBL gene family (Saifi et al. 2018).

Generation of OsRuvBL 1a overexpressing rice transgenics with in-planta transformation method

(i) Plant material and seed sterilization

Healthy and mature seeds of IR64 variety of Oryza sativa were collected from IARI, New Delhi, India and dehusked seeds were sterilized as described by Sahoo and Tuteja (2012).

(ii) Preculture of seeds

Surface-sterilized seeds were precultured in $100 \mathrm{~mL}$ of $1 / 2 \mathrm{MS}$ liquid medium with $0.5 \mathrm{mg} \mathrm{L}^{-1}$ of $\mathrm{GA}_{3}$ in a $250 \mathrm{~mL}$ Erlenmeyer flask incubated in an orbital shaker (Kuhner, Switzerland) set at a constant temperature of $28^{\circ} \mathrm{C}$ for different time periods i.e., $0,3,12,18,24$, and $48 \mathrm{hrs}$. Optimized concentration as surmised from the optical density of Agrobacterium at $600 \mathrm{~nm}(\mathrm{OD}=0.4)$ and co-cultivation duration (up to $24 \mathrm{hrs}$ ) is given in the supplementary tables, S2 and S3.

(iii) Agrobacterium strains and binary vector

Two strains of Agrobacterium tumifaciens (LBA4404 and EHA105) with gene cassette were used for rice seed transformation.

(iv) Preparation of Agrobacterium inoculum

Agrobacterium cells showing absorbance of $0.6-0.8$ at $600 \mathrm{~nm}$ were harvested at $3500 \mathrm{rpm}$ for $20 \mathrm{~min}$ at $4^{\circ} \mathrm{C}$. The harvested bacterial cells were resuspended in co-cultivation medium (Table S7).

(v) Seed transformation

Precultured seeds were dipped in Agrobacterium inoculum for different durations (3, 12, 18 and $24 \mathrm{hrs})$ and kept on shaker $(180 \mathrm{rpm})$ at two different temperatures $\left(23^{\circ} \mathrm{C}\right.$ and $\left.28^{\circ} \mathrm{C}\right)$ with different concentrations of acetosyringone $(0,40,100,200$ and $400 \mathrm{mg} / \mathrm{L})$.

(vi) Effect of hygromycin concentration on germination percentage

Germination percentage was calculated as the average number of seeds germinated over 5 to 10 days' period. The influence of hygromycin was observed on seed germination (Figure S1).

(vii) Seed germination, selection and acclimatization

Agro-infected seeds were inoculated on $1 / 2$ MS Plates, and incubated in the dark at $27^{\circ} \mathrm{C}$. After 2 weeks, the germinated embryos with small shoots were transferred to jam bottles containing $1 / 2$ MS media supplemented with hygromycin for selection and then transferred to vermiculite for hardening. Root 
morphology was closely observed in jam bottles. Putative positive plants which survived on hygromycin were transferred to vermiculite.

(viii) Screening of putative transformants

(a) PCR analysis: The PCR reactions were carried out by using two primer combinations such as hptll specific primers (F'- CAACCTTTTATGAAAAAGCCTGAACTCACCGC and R'- CCACTT AGTCTCGAGTCTATTTCTTTGCCCTCGGACGAG) and CaMV35S promoter forward and gene specific reverse (ACGGATCCCTCGAGATGAGGATCGAGGAGGTGCAGTCGG).

(b) Histochemical analysis of Gus gene expression: Histochemical analysis of Gus gene expression was performed on leaf sheath from transgenic and WT leaf using the procedure described by Vitha et al. (1995).

(ix) Transformation efficiency

Transformation efficiency was calculated based on the presence of the transgene/s in transgenic plants as described by Vitha et al. (1995).

( $x$ ) Optimization of co-cultivation media

To attain the higher transformation efficiency, we studied the effect of different Agrobacterium concentrations (corresponding to the Optical density $0.3,0.4,0.5$ and 0.6 ), $\mathrm{pH}(5.0-6.0$ ) of media, surfactant (Tween 20 and Triton X-100) and growth regulator $\left(\mathrm{GA}_{3}\right)$. The influence of Agrobacterium strains (LBA4404 and EHA105) on the in-planta transformation was also studied.

Copy number analysis

Copy number analysis was performed by using two different approaches of qPCR assay and then its confirmation with Southern hybridization analysis as reported by Passricha et al. (2016).

Analysis of transgenic plants

(i) Expression analysis of OsRuvBL1a gene in transgenic plants

Transcript level of OsRuvBL 1a gene in rice overexpressing transgenic lines was performed by qPCR method with WT plant as control and Actin as reference gene as described by Tuteja et al. (2013).

(ii) Transgene inheritance and homozygous line selection

Transgene inheritance in OsRuvBL1a overexpressing transgenic lines was analyzed by PCR and Gus method. Positive plants were analyzed for homozygous lines by using qPCR approach as described by Passricha et al. (2016) in $T_{1}$ generation (Passricha et al. 2016). List of primers used in this experiment is given in Table S8. 
Different physiological analysis such as germination assay, root/shoot length, chlorophyll retention, dry weight and test grain weight were performed as described by (Garg et al. 2012) and Tuteja et al. (2013).

Biochemical analysis for salinity tolerance of transgenic plants

Biochemical analysis for transgenic lines and WT plants was performed as described by Garg et al. (2012) for salinity (200 mM NaCl) and drought (150 mM mannitol) stress.

In vivo stress tolerance

In vivo stress tolerance in OsRuvBL 1a overexpression transgenic was analyzed as described by Tuteja et al. (2013) for $200 \mathrm{mM} \mathrm{NaCl}$.

\section{Qualitative and quantitative measurement of ions}

Rice OsRuvBL 1a overexpressing transgenic lines with WT control were grown for 15 days in normal tap water. The seedlings were then subjected to salinity stress by addition of $200 \mathrm{mM} \mathrm{NaCl}$ for $12 \mathrm{hrs}$ duration. Crown roots of these plants (stressed and non-stressed) were used for the confocal imaging for $\mathrm{Na}^{+}$and $\mathrm{Ca}^{2+}$ accumulation using the method described by Nath et al., (2016). The mean fluorescence pixel intensity (MFPI) was calculated using five independent measurements of the respective fluorescent confocal images using ImageJ program (Collins 2007).

\section{Cell Viability}

15 days old seedlings of WT and OsRuvBL 1a transgenics were subjected to salinity ( $200 \mathrm{mM} \mathrm{NaCl})$ and drought ( $150 \mathrm{mM}$ mannitol) stress for 12 hrs duration. Crown roots of these seedlings were analyzed for cell viability by staining of roots using propidium iodide ( $3 \mu \mathrm{g} / \mathrm{mL}$; Hi Media) for 1 min as described by Nath et al. (2016).

\section{Identification of interacting partners}

Interacting partners of OsRuvBL1a were identified by yeast two-hybrid $(\mathrm{Y} 2 \mathrm{H})$ assay. The ORF of OsRuvBL1a and another member of this family, OsRuvBL2a were cloned in frame in both the pGBKT7 and $\mathrm{pGADT7}$ vectors at Nde / and EcoR / restriction sites. Rice cDNA library was cloned in pGADT7 vector. The yeast two-hybrid assay was performed as described by Fields and Song (1989. Few interacting partners from $\mathrm{Y} 2 \mathrm{H}$ results were validated with Bimolecular fluorescence complementation (BiFC) assay for one-to-one interaction as well as for authenticity of $\mathrm{Y} 2 \mathrm{H}$ results. Selected interacting partners were cloned in PSPYNE vector and OsRuvBL 1a was cloned in PSPYCE vector for BiFC. Abaxial surface of Nicotiana benthamiana leaves were co-transformed with Agrobacterium cells containing PSPYCE and pSPYNE constructs having OsRuvBL1a and selected interacting partners along with p19 RNAi suppressor gene construct as described by Passricha et al. 2019. Transformed plants incubated at $22^{\circ} \mathrm{C}$ for 2 days 
and then screened with fluorescence microscopy for interactions. pSPYCE and pSPYNE empty vectors were used as negative control.

Agrobacterium cells containing each of the OsRuvBL1a-pSPYCE construct \& LecRLK-SPYNE construct were inoculated in $5 \mathrm{~mL}$ LB containing rifampicin, Kanamycin and Chloramphenicol. Agrobacterium containing p19 RNAi suppressor gene construct were similarly inoculated in $5 \mathrm{~mL}$ LB media containing rifampicin, gentamycin, and kanamycin using a $2 \mathrm{~mL}$ syringe, the Agrobacterium cocktail was injected into the abaxial surface of a leaf of Nicotiana benthamiana. Plants were then kept at $22^{\circ} \mathrm{C}$ and screened after 2 days using a fluorescence microscope (ZEISS AXIO Imager.Z2 microsystems from Germany).

\section{Statistical analysis}

Average 50 seeds, in three replications were used for each combination and data represented in Table S2 and S4 is the mean \pm SE calculated by using MSTAT computer program. Least significant difference (LSD) among the means at $\mathrm{P}>0.05$ level of probability was considered as significant. For confocal study, data are presented as relative units of pixel intensities and the average fluorescence intensity was calculated via three independent measurements of confocal images using ImageJ software $(\mathrm{NIH})$ in arbitrary units. In addition, respective back-ground pixel intensity (unstained area) of the confocal image was also considered to calculate the final mean fluorescence pixel intensity using ImageJ $(\mathrm{NIH})$. For all graphs, data were analyzed by ANOVA (Analysis of Variance). Dunnett's multiple comparison test was used to test the significance between WT and transgenic plants by using GraphPad Prism software version 6.0. The statistical significance was represented as " " " and "**” for $p<0.05$ and $p<0.01$ respectively.

Locus ID of OsRuvBL1a: LOC_Os01g62040

\section{Results:}

\section{Gene Selection and characterization}

OsRuvBL 1a gene has been selected based on our preliminary studies in which it was found to be an abiotic stress-responsive gene (Saifi et al. 2018) and thus, make it a potential candidate gene mediating abiotic stress tolerance in rice. OsRuvBL 1a encodes for a $55 \mathrm{kDa}$ protein (Fig. 1 a \& b). Recently, it has been reported that purified recombinant protein showed nucleic acid independent ATPase (Fig. 1 c \& d) and ATP dependent DNA unwinding activity (Fig. 1e) (Saifi et al. 2018).

\section{Development of in-planta transformation method for rice with mature seeds}

OsRuvBL 1a overexpressing rice transgenics were produced by using improved in-planta transformation method, which is less labour-intensive, easy and fast, using the mature rice seeds as explant. This report briefly describes the OsRuvBL1a overexpression transgenic of rice by using this improved in-planta method and its optimization for various factors. 
(i) Effect of in-planta transformation and hygromycin concentration on germination percentage

The hygromycin concentration of $20 \mathrm{mg} / \mathrm{L}$ was observed as lethal (Minimum Inhibitory Concentration, MIC) as more than $50 \%$ of seeds failed to germinate (Table S1). Later same concentration $(20 \mathrm{mg} / \mathrm{L})$ was used for selecting the putative transformed seedlings (Fig. 2a). Wild type control and non-transgenic seedlings died on hygromycin selection (Fig. 2ai and 2aiii) whereas putative transgenic plants survived and were selected (Fig. 2aii and 2aiv).

(ii) Optimization of acetosyringone concentration, co-cultivation duration and effect of different strains on in-planta transformation efficiency

Different concentrations of acetosyringone $(0,40,100,200$ and $400 \mathrm{mg} / \mathrm{L})$ were supplemented with Agrobacterium inoculum to study the effect of acetosyringone concentration on transformation efficiency of this method. Among the different concentrations and co-cultivation duration, Agrobacterium strain LBA4404 with $200 \mathrm{mg} / \mathrm{L}$ of acetosyringone incubated for 24 hrs showed maximum transformation of $32.7 \pm 0.9 \%$ after PCR with $h p t / l$ gene specific primers and CaMV35S forward and gene specific reverse primers, respectively (Fig. 2bi and 2bii) and Gus screening (Fig. 2c) (Table S2). Similarly, for Agrobacterium strain EHA105 mediated transformation, the same concentration of acetosyringone (200 $\mathrm{mg} / \mathrm{L}$ ) resulted in maximum transformation of $36.0 \pm 2.0 \%$ when incubated for 24 hrs (Table S3).

(iii) Influence of pre-culture duration on in-planta transformation efficiency

The transformation efficiency was observed for different durations of pre-culture $(0,3,12,18,24$ and 48 hrs). A pre-culture period of $24 \mathrm{hrs}$ was found to be the most suitable for T-DNA delivery, resulting in a significant increase in the transformation frequency from $32.7 \pm 0.9 \%$ to $41.33 \pm 3.5 \%$ for LBA4404 strain (Table S4).

(iv) Optimization of co-cultivation media for in-planta transformation method

1. Agrobacterium inoculum concentration: Highest percentage of transformed plants was observed when optical density (O.D.) of Agrobacterium inoculum was kept 0.4 at $600 \mathrm{~nm}$. Further increase in O.D. resulted in a decrease in transformation efficiency.

2. Optimization of $\mathrm{pH}: \mathrm{pH}$ of co-cultivation medium is the authoritative divisor for the expression of vir genes and T-DNA transfer. In this study we obtained the highest efficiency at pH 5.8.

3. Surfactants: Best standard conditions ( $24 \mathrm{hrs}$ incubation with $200 \mathrm{mg} / \mathrm{L}$ acetosyringone concentration) were chosen to test the effect of different surfactants on transformation efficiency. Two surfactants (Tween 20 and Triton X-100) were applied with three different concentrations $(0.05$, 0.1 and $0.2 \%$ ). The application of surfactants at higher concentration showed continuous decline in the transformation efficiency.

4. Growth Regulator: A growth regulator, $\mathrm{GA}_{3}$ in co-cultivation medium, did not show any significant change in transformation efficiency. 
This in-planta method is strain-independent (Table S5) because both the strains of Agrobacterium (LBA4404 and EHA105) showed maximum transformation efficiency by 24 hrs co-cultivation. We have optimized that rice seeds pre-cultured for 24 hrs in MS medium with $\mathrm{pH}-5.8$ and co-cultivated with Agrobacterium cells (at O.D. $=0.4$ ) for $24 \mathrm{hrs}$ in the presence of $200 \mathrm{mg} / \mathrm{L}$ acetosyringone showed maximum transformation efficiency. The transformed seeds were selected on $20 \mathrm{mg} / \mathrm{L}$ hygromycin supplemented MS medium to narrow down the selection process.

\section{Copy number}

Results of both the qPCR and Southern blot hybridization methods for copy number analysis of putative transgenic lines ( $L-1$ to $L-5$ ) showed that L- $1, L-3, L-4$ and L-5 have single copy insertion whereas L-2 showed two copies of target gene in rice genome (Fig. $2 \mathbf{d}$ and $\mathbf{2 e}$ ). Based on these results single copy lines L-1, L-3, L-4 and L-5 were used for further analysis.

\section{Expression analysis of OsRuvBL1a in transgenic plant}

Four transgenic plants (L-1, L-3, L-4 and L-5) overexpressing OsRuvBL 1a gene were screened to identify the transgenic lines which showed higher expression for OsRuvBL 1a gene by qPCR method. Out of 4 transgenic lines, transcript level quantification showed that line L-1, L-4 and L-5 have the highest expression for the transgene with around 13, 23 and 15 folds' increase, respectively (Fig. 2f).

\section{Transgene inheritance}

The segregation pattern for T-DNA was tested as a single dominant Mendelian gene segregation method. About 45 seeds were taken from each line ( $L-1, L-4$ and $L-5)$ and the results were validated using the

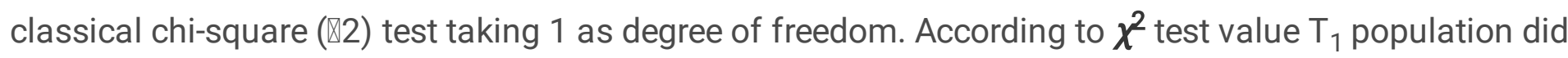
not follow the Mendelian segregation pattern because average chi square value was much higher than table value (20.90) (Table S6). Gus histochemical assay was also performed in $\mathrm{T}_{1}$ seeds and seedlings for the positive transgenics and it showed the formation of blue coloration in transgenic seeds and seedlings (Fig. 2g).

\section{Homozygous transgenic line}

The identification of homozygous lines was performed with qPCR in $T_{1}$ transgenic plants for the lines $L-1$, L-4 and L-5 for 14 plants. Out of 14 plants in the line L-1, four plants (namely, L1.1, L1.2, L1.6 and L1.10) possessed 2 copies (Fig. $2 \mathrm{~h}$ ). In the line L-4, three plants (namely, L4.5, L4.7 and L4.10) possessed 2 copies of OsRuvBL1a (Fig. 2i). Similarly, in the line L-5,3 three plants (L5.2, L5.6 and L5.9) showed 2 copies for the transformed gene and hence considered as homozygous (Fig. 2j).

\section{Physiological analysis of OsRuvBL 1a transgenic plants}

To examine the role of overexpression of OsRuvBL 1a gene in conferring the abiotic stress tolerance in rice, comparative analysis of several physiological tests was performed in WT type and OsRuvBL1a 
overexpressing transgenic lines (L1, L4 and L5) under salinity and drought stress conditions. Germination assay revealed that under stress-free control conditions there was no significant difference in germination pattern in WT as compared to OsRuvBL1a transgenic lines (Fig. 3a-d), however, when grown under salinity $(200 \mathrm{mM} \mathrm{NaCl})$ and drought $(150 \mathrm{mM}$ mannitol) stress the transgenic lines were germinated earlier than the corresponding WT. The seeds exposed to salinity stress had the germination percentage of $\sim 60 \%, 75 \%$ and $55 \%$ (Fig. 3 d); whereas, under drought stress the germination rate was $68 \%, 80 \%$ and $62 \%$ for lines L-1, L-4 and L-5, respectively (Fig. 3 d). The WT seeds exhibited only $\sim 15 \%$ germination under both the stress conditions (Fig. 3d). High root/shoot ratio and strong root architecture helps plant to overcome the salinity (Fig. 3e) and drought stress conditions (Fig. 3f). Transgenic lines (L-1, L-4 and L5) showed root/shoot ratio of 1.2, 1.3 and 1.5, respectively under salinity stress (Fig. 3g) and 0.7, 0.8 and 0.8 , respectively under drought stress (Fig. $\mathbf{3 g}$ ). Whereas WT plants showed root/shoot ratio of 0.2 and 0.6 under salinity and drought stress (Fig. $\mathbf{3 g}$ ). Higher dry weight of plant indicates lower water retention capacity. Lines L-1, L-4 and L-5 showed 1.7, 1.8 and 1.5-fold lesser dry weight, respectively than WT plants under the salinity stress conditions (Fig $3 \mathrm{~h}$ ). Under drought stress, all the three transgenic lines showed 1.8-fold lesser dry weight as compared to WT plants (Fig. 3h), whereas under the normal control conditions, transgenic lines and WT plants did not have significant difference in their respective dry weight (Fig. 3h). Stress conditions affected the photosynthetic machinery of plants and caused chlorophyll degradation (Fig. 3i-l). Total chlorophyll content measured in WT and OsRuvBL 1a transgenic lines showed about 5 -fold high chlorophyll content in all the three transgenic lines ( $L-1, \mathrm{~L}-4$ and L-5) as compared to WT plants during salinity stress (Fig. 3j). Under drought stress, lines L-1and L-5 showed about 2.5-fold higher retention of chlorophyll content as compared to WT plants, whereas L-4 line showed 1.5-fold higher chlorophyll retention (Fig. 3I).

\section{Biochemical analysis of OsRuvBL1a transgenic plants}

Abiotic stresses affect ROS machinery in plants and it was detected and quantified by some biochemical tests such as malondialdehyde (MDA) accumulation, proline, $\mathrm{H}_{2} \mathrm{O}_{2}$ content and cell membrane stability in $\mathrm{T}_{2}$ generation (Fig. 4a-l). Generation of $\mathrm{H}_{2} \mathrm{O}_{2}$ and MDA in a cell is the marker of negative effects of stress since these molecules are result of cell degradation. This study showed significantly less $\mathrm{H}_{2} \mathrm{O}_{2}$ and MDA accumulation in transgenic line L-4 under both the salinity (Fig. 4 a \& b) as well as the drought stress (Fig. $\mathbf{4} \mathbf{g} \mathbf{\&}$ ) as compared to the corresponding WT plants. To overcome the water deficit condition imposed by the salinity and drought stress, plants are known to accumulate osmolytes such as proline.

OsRuvBL 1a transgenic lines showed higher level of proline content as compared to WT with line L-4 showing maximum accumulation of proline under both salinity (Fig. 4c) and drought stresses (Fig. 4i). All transgenic lines showed higher electrolyte retention as compared to the WT plants with line L-4 showing maximum electrolyte retention under salinity stress (Fig. 4d) and line L-1 showed maximum electrolyte retention under drought stress (Fig. 4j). Overall these observations suggest the reduced effect of stress and damage to cell membrane in transgenic lines and confirm the role of OsRuVBL1a in maintenance of the cell membrane stability under the abiotic stresses. The activity of ROS scavenging enzymesascorbate peroxidase (APX) and catalase were also estimated. Both the enzymes APX and catalase use 
$\mathrm{H}_{2} \mathrm{O}_{2}$ as substrate to reduce it into water. Under salinity stress condition transgenic line L-4 showed higher APX and catalase activities as compared to WT plants (Fig. 4 e \& f). Under drought stress the transgenic line L-4 showed maximum activity of APX and catalase (Fig. $4 \mathbf{k} \& \mathbf{l})$. These biochemical analyses showed improved ROS scavenging machinery and maintenance of cell integrity in transgenic lines as compared to WT plant under stress conditions.

\section{Determination of ion content and cell death in response to abiotic stresses}

The quantification of ions accumulation and cell death in plant tissue is another method to observe the effect of stress conditions on plants. In this study, we measured the effect of salinity stress and drought stress on rice seedlings. Sodium ion $\left(\mathrm{Na}^{+}\right)$accumulation in root tissue during salinity stress was studied as a method for quantification of $\mathrm{Na}^{+}$ion imbalance in plants during stress conditions. CoroNa green dye was used for the non-destructive monitoring of relative accumulation of $\mathrm{Na}^{+}$ion in roots of WT and OsRuvBL 1a overexpressing transgenic lines by using the confocal microscopy. The transgenic line L-5 showed the least fluorescence and lines L-1 and L-4 also showed lesser fluorescence as compared to WT roots under salinity stress (Fig. 5 a \& b). These results suggest that more $\mathrm{Na}^{+}$ion accumulation occurred inside WT roots during salinity stress as compared to the transgenic lines. For the study of calcium ion $\left(\mathrm{Ca}^{2+}\right)$ accumulation an esterified form of Fluo-4, Fluo4-AM was used. Fluo4-AM is a $\mathrm{Ca}^{2+}$ sensitive fluorescent probe indicator which shows increase in fluorescence upon binding with cytosolic $\mathrm{Ca}^{2+}$. Confocal microscopy of WT and transgenic roots under salinity stress was used to observe the cytosolic $\mathrm{Ca}^{2+}$ accumulation. Higher fluorescence in WT roots as compared to transgenic line L-1 suggested an accumulation of more cytosolic $\mathrm{Ca}^{2+}$ in WT roots under stress conditions (Fig. $\mathbf{5}$ c \& d). Stress conditions also cause ionic imbalance and oxidative stress that make the cells inviable. Cell viability can be studied in plant root in non-destructive manner by using propidium iodide (PI) dye. $\mathrm{PI}$ is a membrane impermeant dye and hence viable cells show less or no fluorescence whereas it penetrates in dead cells and intercalates in double stranded DNA and provides florescence on excitation. The cell viability study of rice root tissue under salinity and drought conditions showed higher fluorescence in roots of WT plants as compared to transgenic lines under salinity stress (Fig. $\mathbf{5}$ e \& f) and drought stress (Fig. $\mathbf{5} \mathbf{g}$ \& h). These results showed that stress conditions caused higher cell death in WT plants as compared to overexpressing transgenic lines. These studies suggest the role of OsRuvBL 1a in providing stress tolerance under stress conditions at ionic and cell viability level.

\section{Salinity and drought stress tolerance under in vivo conditions}

WT and the transgenic plants (L-1, L-4 and L-5) overexpressing OsRuvBL1a gene showed significantly different behaviors under salinity and drought stress (Fig. 6). At day-1, all the plants of same age were exposed to salinity stress $(200 \mathrm{mM} \mathrm{NaCl})$ as well as drought stress (non-availability of water) as shown in Fig. 6 a \& c. On day 20 salinity stress, the WT plant could not survive salinity stress till 20 days, on the other hand, the OsRuvBL1a transgenic plants withstood the stressed condition (Fig. 6b). Among the 
transgenics, the L-4 line was found to be the most tolerant line. For drought stress, WT plant died after 15 days while OsRuvBL1a-overexpressing transgenic plants were thriving (Fig. 6d).

Isolation and identification of interacting partners of OsRuvBL1a through yeast two-hybrid method

Physiological and biochemical analysis of overexpressing transgenic lines showed better performance as compared to WT under salinity and drought stress. To understand the working mechanism of

OsRuvBL1a, its interacting partners were identified by using yeast two-hybrid method. Sequential selection of transformed yeast on two drop outs (2-DO) (-Leu, -Trp), 3-DO (-His, -Leu, -Trp) and 4-DO (-Ade, -His, -Leu, -Trp) media plates followed by filter lift assay showed positive interacting clones. The colonies found positive on X-gal assay were sequenced and analyzed using rice genome to find the interacting partners of OsRuvBL1a enlisted as Table 1. Y2H (one-to-one interaction) as well as BiFC studies showed that OsRuvBL1a does not self-interact whereas, it exhibits strong interaction with another member of its family, OsRuvBL2a. The OsRuvBL1a-OsRuvBL2a interaction led to the formation of a hetro-oligomeric structure by these proteins. BiFC based one-to-one interaction study of OsRuvBL1a with few selected partners showed positive interactions and validate the $\mathrm{Y} 2 \mathrm{H}$ results (Figure S2). These validated interacting partners may have some direct or indirect role in conferring the stress tolerance to the plants. 
Table 1

List of interacting partners of OsRuvBL1a

\begin{tabular}{|c|c|c|c|}
\hline Class & Locus ID & Gene Name & Putative Function \\
\hline \multirow[t]{7}{*}{$\begin{array}{l}\text { Hormonal } \\
\text { Signaling }\end{array}$} & LOC_Os08g44510 & $\begin{array}{l}\text { UDP-N- } \\
\text { acetylglucosamine- } \\
\text { peptide N-acetylglucos- }\end{array}$ & Negative regulator of GA signaling \\
\hline & & $\begin{array}{l}\text { aminyltransferase } \\
\text { SPINDLY }\end{array}$ & \\
\hline & LOC_Os10g31770 & $\begin{array}{l}\text { START domain } \\
\text { containing protein }\end{array}$ & $\begin{array}{l}\text { ABA signaling. Biotic and Abiotic } \\
\text { stress tolerance }\end{array}$ \\
\hline & LOC_Os01g13030 & $\begin{array}{l}\text { OsIAA3 - Auxin- } \\
\text { responsive Aux/IAA } \\
\text { gene family member }\end{array}$ & Auxin signaling \\
\hline & LOC_Os07g28480 & $\begin{array}{l}\text { glutathione S- } \\
\text { transferase }\end{array}$ & $\begin{array}{l}\text { Auxin and oxidative stress- } \\
\text { signaling }\end{array}$ \\
\hline & LOC_Os03g20790 & ethylene-insensitive 3 & Me-JA and SA signaling \\
\hline & LOC_Os12g43600 & $\begin{array}{l}\text { RNA recognition motif } \\
\text { containing protein }\end{array}$ & $\begin{array}{l}\text { Response to stress and RNA } \\
\text { silencing and splicing }\end{array}$ \\
\hline \multirow[t]{10}{*}{$\begin{array}{l}\text { Gene } \\
\text { Regulation }\end{array}$} & LOC_Os03g60080 & $\begin{array}{l}\text { NAC domain-containing } \\
\text { protein } 67\end{array}$ & $\begin{array}{l}\text { Stress-responsive transcription } \\
\text { factor }\end{array}$ \\
\hline & LOC_Os06g39700 & $\begin{array}{l}\text { DNA-directed RNA } \\
\text { polymerase subunit } \\
\text { alpha }\end{array}$ & Transcription \\
\hline & LOC_Os01g63980 & $\begin{array}{l}\text { ZOS1-17 - } \mathrm{C} 2 \mathrm{H} 2 \text { zinc } \\
\text { finger protein }\end{array}$ & Transcription \\
\hline & LOC_Os01g54100 & CK1_CaseinKinase_1a.2 & Transcription elongation \\
\hline & LOC_Os05g41110 & Ribosomal protein L7Ae & Translation \\
\hline & LOC_Os01g24690 & $\begin{array}{l}\text { 60S ribosomal protein } \\
\text { L23A }\end{array}$ & Translation \\
\hline & LOC_Os07g40580 & $\begin{array}{l}\text { eukaryotic translation } \\
\text { initiation factor } 5 \mathrm{~A}\end{array}$ & Translation \\
\hline & LOC_Os06g43210 & $\begin{array}{l}\text { zinc finger, } \mathrm{C} 3 \mathrm{HC} 4 \text { type } \\
\text { domain containing } \\
\text { protein }\end{array}$ & Ubiquitination pathway \\
\hline & LOC_Os01g62230 & $\begin{array}{l}\text { Core histone } \\
\mathrm{H} 2 \mathrm{~A} / \mathrm{H} 2 \mathrm{~B} / \mathrm{H} 3 / \mathrm{H} 4 \\
\text { domain containing } \\
\text { protein }\end{array}$ & Chromatin remodeling \\
\hline & LOC_Os06g45390 & Expressed protein & $\begin{array}{l}\text { RNA binding, post transcriptional } \\
\text { gene regulation and translation }\end{array}$ \\
\hline
\end{tabular}




\begin{tabular}{|c|c|c|c|}
\hline Class & Locus ID & Gene Name & Putative Function \\
\hline & LOC_Os01g50100 & $\begin{array}{l}\text { ABC transporter, ATP- } \\
\text { binding protein }\end{array}$ & $\begin{array}{l}\text { Multiple drug resistance, } \\
\text { Telomerase reverse transcriptase } \\
\text { activity, Activation of double } \\
\text { strand break machinery }\end{array}$ \\
\hline \multirow{6}{*}{$\begin{array}{l}\text { Cellular } \\
\text { Mechanism } \\
\text { and } \\
\text { Development }\end{array}$} & LOC_Os05g50370 & $\begin{array}{l}\text { DnaJ domain } \\
\text { containing protein }\end{array}$ & $\begin{array}{l}\text { Chaperon and protein } \\
\text { transportation by vesicle coat } \\
\text { proteins }\end{array}$ \\
\hline & LOC_Os06g12580 & Pro-resilin precursor & Chaperon \\
\hline & LOC_Os11g47970 & $\begin{array}{l}\text { AAA-type ATPase } \\
\text { family protein }\end{array}$ & $\begin{array}{l}\text { Rubisco Activase, A chaperon for } \\
\text { Rubisco under Heat stress }\end{array}$ \\
\hline & LOC_Os07g05810 & Glycine-rich protein & $\begin{array}{l}\text { Peroxisome biogenesis, transport } \\
\text { mechanism }\end{array}$ \\
\hline & LOC_Os12g19381 & $\begin{array}{l}\text { Ribulose bisphosphate } \\
\text { carboxylase small } \\
\text { chain }\end{array}$ & Involved in $\mathrm{CO}_{2}$ metabolism \\
\hline & LOC_Os08g15170 & $\begin{array}{l}\text { ATP synthase epsilon } \\
\text { chain }\end{array}$ & ATP synthesis \\
\hline \multirow[t]{4}{*}{$\begin{array}{l}\text { Stress } \\
\text { Responsive }\end{array}$} & LOC_Os08g03290 & $\begin{array}{l}\text { glyceraldehyde-3- } \\
\text { phosphate } \\
\text { dehydrogenase }\end{array}$ & $\begin{array}{l}\text { glycolytic pathway, response to ER } \\
\text { stress, heat, } \mathrm{H}_{2} \mathrm{O}_{2} \text {, oxidative, salt } \\
\text { stress, sucrose and temperature } \\
\text { stimuli }\end{array}$ \\
\hline & LOC_Os08g19980 & $\begin{array}{l}\text { NBS-LRR disease } \\
\text { resistance protein }\end{array}$ & $\begin{array}{l}\text { R-gene involved in biotic stress } \\
\text { regulation }\end{array}$ \\
\hline & LOC_Os03g28940 & $\begin{array}{l}\text { ZIM domain containing } \\
\text { protein }\end{array}$ & Jasmonate Signalling \\
\hline & LOC_0s07g48500 & $\begin{array}{l}\text { Stress-responsive } \\
\text { protein }\end{array}$ & $\begin{array}{l}\text { Stress-responsive and ROS } \\
\text { scavenging }\end{array}$ \\
\hline
\end{tabular}

\section{Discussion:}

In a recent study we have reported that OsRuvBL1a exhibits nucleic acid independent ATPase and DNA unwinding activity (Saifi et al. 2018). ATPase activity in other systems has been reported in the presence of ssDNA and dsDNA (Ahmad and Tuteja 2012; Gribun et al. 2008; Kanemaki et al. 1997) but nucleic acid independent activity has not been reported yet. To functionally validate the OsRuvBL1a gene under stress conditions, overexpressing transgenic lines were generated with the help of a newly developed Agrobacterium-mediated in-planta transformation method.

Many in-planta transformation methods are already in use for rice (Ratanasut et al. 2017; Supartana et al. 2005), brinjal (Subramanyam et al. 2013), maize (Hiei et al. 2006) and field bean (Keshamma et al. 2011). The in-planta rice transformation protocol used in present study was improvised to reduce labor 
and time of the transformation protocol that too with an improved transformation efficiency. The optimization of transformation efficiency is primary requirement for a transformation protocol of choice. The transformation efficiency is a factor of media composition, incubation period, acetosyringone concentration and seed treatments (Mayavan et al. 2013). Our method is based on the principle that transformation of meristematic cells at an early stage makes the inheritance stable from the parent generation to the next generation (Sajib et al. 2008). In this method, rice seeds were allowed to germinate in MS liquid medium with Agrobacterium to facilitate the integration of transgene during germination, as meristematic cells are rapidly dividing and highly receptive at this stage (Gordon-Kamm et al. 2002; Villemont et al. 1997). Similar increase in transformation efficiency has also been reported in several crops including wheat, tomato and barley (Rai et al. 2011).

A number of factors such as medium characteristics (like $\mathrm{pH}$, sugar concentration, salt concentration), bacterial suspension, acetosyringone amount and growth hormones influence the transformation efficiency of an in-planta transformation method. The negligible effect of different strains of $A$. tumefaciens strain (LBA4404 and EHA105) on germination percentage of IR64 variety seeds also supports the hypothesis. MIC of hygromycin provides add-on tools for selecting the transgenic plants (Tuteja et al. 2012). The $\mathrm{pH}$ of the medium is an important determinant for efficient growth of Agrobacterium cells and transformation of SAM cells. Media set at pH 5.8 worked best for the protocol used in the study. Fierer and Jackson (2006) also reported that acidic pH is optimum for bacterial growth. Agrobacterium cell concentration is another critical component to be optimized for maximum transformation efficiency. An O.D. of 0.4 at $600 \mathrm{~nm}$ was found to be the optimum concentration for Agrobacterium growth, since it contained highly active cells in their log phase of development (McCormac et al. 1998; Zhou et al. 2003). Another major component of co-cultivation media is acetosyringone that provides chemotaxis to the Agrobacterium and activates the virgenes present on the helper plasmid (Kumlehn et al. 2006; Winans et al. 1988). In this study, concentration of acetosyringone was optimized by performing the in-planta seed transformation with various concentrations of acetosyringone and 200 $\mathrm{mg} / \mathrm{L}$ acetosyringone was found to be the optimum concentration after $24 \mathrm{hrs}$ of co-cultivation. High concentration of acetosyringone showed a reduction in total seed germination percentage which ultimately reduced the transformation efficiency probably because of the supra-optimal concentration of non-polar solvents (alcohol/DMSO) (Antony et al. 2015). Few reports claimed the influence of growth regulators such as gibberellic acid on the transformation efficiency by breaking the dormancy of rice seeds (Vieira et al. 2002), although in this study the concentration of GA3 used did not make any significant change. The addition of surfactant in the inoculation media increases the transformation efficiency by reducing the surface tension of water and facilitated the attachment of Agrobacterium cells to the surface of explant as well as increased the time of attachment by eliminating the inhibitory substances (Huang and Wei 2005). However, we observed lower transformation efficiency in the presence of surfactants. Similar results for surfactant have been reported by Hosein et al. (2012) (Hosein et al. 2012). Pre-culture medium increases the number of transformation event by promoting cell division, because actively dividing cells are amenable to T-DNA delivery and integration (Sangwan et al. 1991). In addition, pre-culture also prevents the negative effect of Agrobacteria and selection agent in the seed 
transformation. Similarly, previous reports also claimed an improvement of transformation efficiency due to pre-culturing (Mariashibu et al. 2013). After optimization of several factors, we conclude that this newly developed in-planta transformation method is better than previous methods because it is less labor-intensive, less time-consuming, strain-independent and cost-effective as well.

Salinity and drought inhibit seed germination and cause retarded root/shoot growth due to the osmotic imbalance in plant cells (Khan and Hemalatha 2016; Munns 2002; Passricha et al. 2019b; Ra et al. 2016). The transgenic plants overexpressing OsRuVBL1a showed higher seed germination, longer primary roots and high root/shoot ratio that overcame the osmotic imbalance. The transgenic lines showed higher chlorophyll content, cell membrane stability and higher water retention capacity as compared to the WT plants under stress condition. These improved features assure the survival of plants under stressed condition as reduction in chlorophyll degradation (Mao et al. 2012), maintenance of membrane integrity and eletrolyte balance in cell is a necessity to withstand the stress conditions.

Similarly, overexpressing OsRuvBL1a transgenic plants showed lesser accumulation of ROS as compared to WT plants under salinity and drought stress, suggesting the role of OsRuvBL1a in regulation of ROS scavenging pathway. $\mathrm{H}_{2} \mathrm{O}_{2}$ is one of the major products of ROS and its higher accumulation in plants showed the negative effects of stress on plants (Gill and Tuteja 2010; Huda et al. 2013; Yadav et al. 2018). OsRuvBL1a transgenic plants showed lower accumulation of $\mathrm{H}_{2} \mathrm{O}_{2}$ in stress conditions and it is in agreement with the previously reported studies that states lesser accumulation of ROS helps the plants in stress tolerance (Huda et al. 2013; Tuteja et al. 2013). In addition, the transgenic plants showed higher activity of enzymes such as catalase and ascorbate peroxidase which are key players in regulation of ROS level in cell (Gill and Tuteja 2010) and their high activity in transgenic plants supports the low level of $\mathrm{H}_{2} \mathrm{O}_{2}$ of these plants even under stress conditions. This study also showed a low level of MDA formation due to the less lipid peroxidation which provides membrane stability (Huda et al. 2013; WongEkkabut et al. 2007) and high level of proline accumulation. Proline is an osmolyte that helps the cells to increase its water retention capacity under physical and physiological stresses (Garg et al. 2012; Tu et al. 2014).

Salinity stress creates ionic imbalance in the cells, thereby, leading to the cell death. The measurements of intracellular ion concentration in transgenic plants revealed that the OsRuVBL 1a encoding gene is involved in lowering of the accumulation of sodium ions inside cells as compared with the corresponding wild types grown in identical conditions. Lower sodium ion accumulation in the salinity tolerant plants as compared to susceptible plants has also been reported earlier studies also (Kavitha et al. 2012; Nath et al. 2016; Passricha et al. 2020; Zhang et al. 2011). As a stress tolerance mechanism the plants are known to sequester excess $\mathrm{Na}^{+}$ions inside the intracellular compartments to protect the essential organelles and molecules from their deleterious effects (Blumwald 2000; Flowers and Colmer 2008).

$\mathrm{Ca}^{2+}$ ion is another important ion that plays an important role in regulating cell physiology as a messenger of numerous cell signalling pathways. Our results revealed a higher concentration of $\mathrm{Ca}^{2+}$ ions in WT roots than the transgenic lines grown in identical conditions. These results can be correlated 
with higher rate of cell deaths in WT plants grown under stress conditions. These results further reinforces that OsRuvBL1a is involved in regulation of many cellular activities since the $\mathrm{Ca}^{2+}$ ion flux has been reported to initiate onset of various cellular pathways, which initially protect cells from stress but eventually lead to cell death under continuous stress conditions (Lin et al. 2008).

Hybridization studies revealed that OsRuvBL1a interacts with OsRuvBL2a, which is another member of the RuvB family, however no evidence of inter-molecular interaction is found between two OsRuvBL1a molecules. RuvB1 and RuvB2 interactions are also been reported earlier that results in the formation of heterohexameric ring structure (Abrahao et al. 2021; Cheung et al. 2010; Niewiarowski et al. 2010; Schorova et al. 2019). Formation of a complex structure as a result of OsRuvBL1a and OsRuvBL2a interaction needs to be looked upon by structural studies.

The interacting partners of OsRuvBL1a that might play some direct or indirect role in the stress tolerance have been listed in Table 1. Based upon the results of the dihybrid analysis, a hypothetical model has been proposed (Fig. 7), which highlights the possible importance of OsRuvBL1a in imparting the stress tolerance to the rice crop. Reactive oxygen species (ROS) and lipid peroxidase are efficient markers of stress (Sewelam et al. 2016). The genes involved in the ROS scavenging pathway are known to be controlled by OsRuvBL1a via hormonal regulation as surmised by the interaction of the OsRuvBL1a with SPINDLY (Furstenberg-Hagg et al. 2013; Shimada et al. 2006), START (Hubbard et al. 2010; Klingler et al. 2010), elF5a (Wang et al. 2012) OsIAA3 and ZIM domain containing proteins (Ishiga et al. 2013; Wang et al. 2017).

OsRuvBL1a directly interacts with stress responsive transcription factor such as NAC domain containing protein (Huang et al. 2016; Rahman et al. 2016) and EIN3 is involved in the expression of stressresponsive genes to cope with the abiotic as well as biotic stress through MeJA-induced leaf senescence (Cho and Yoo 2014; Zhang et al. 2016). OsRuvBL1a has also been shown to interact with core histone domain containing protein $\mathrm{H} 2 \mathrm{~A} / \mathrm{H} 2 \mathrm{~B} / \mathrm{H} 3 / \mathrm{H} 4$ which are part of the of nucleosome core. In addition, the OsRuvBL1a also interacts with the $\mathrm{C} 3 \mathrm{HC} 4$ zinc finger protein, which is known to be involved in chromatin remodeling by monoubiquitination of histone H2B (Liu et al. 2007), for accessibility of DNA-to-DNA damage repair machinery for repair of any damage caused due to ROS and lipid peroxidation. Earlier studies in other systems such as yeast and human have already shown RuvB1 as a component of different chromatin remodelling complexes (Gorynia et al. 2011; Jeganathan et al. 2015; Jin et al. 2005). However, no such study has been carried out in the plant system, and our study may provide a lead to further explore the role of OsRuvBL1a as a part of some chromatin remodelling complex and therby effectuating the stress tolerance in rice.

OsRuvBL1a directly interacts with R-gene NBS-LRR in NBS-LRR-Avr complex to provide biotic stress tolerance by facilitating the expression of R-gene responsive genes involved in hypersensitive response (DeYoung and Innes 2006; Marone et al. 2013; McHale et al. 2006; Song et al. 2017). OsRuvBL1a directly interacts with stress-responsive proteins such as GST (Glutathione-S-Transferase) involved in xenobiotic and peroxide detoxification (Dixon et al. 2009; Raza 2011), glyceraldehyde-3-phosphate dehydrogenase 
response to various abiotic stimuli like ER stress, temperature, $\mathrm{H}_{2} \mathrm{O}_{2}$, oxidative stress, redox state, salt stress and sucrose stimulus (Kappachery et al. 2014), glycine-rich protein (Ortega-Amaro et al. 2014; Yao et al. 2016) and chaperon proteins such as dnaJ (Wang et al. 2015; Zhao et al. 2010) and pro/resilin precursor protein (Vitamvas et al. 2012; Yang et al. 2016). OsRuvBL1a also helps in the improvement of photosynthetic efficiency by interacting with Rubisco activase that is involved in the removal of inhibitory sugars from Rubisco under normal cellular conditions and also acts as a chaperon during heat stress (Chen et al. 2015; Keown et al. 2013; Kumar et al. 2016).

This study focused on the detailed characterization of rice homolog of RuvBL1 (OsRuvBL1a). OsRuvBL1a exhibits ATPase and helicase activities that could be essential to perform cellular functions. Transgenic Rice plants over-expressing OsRuvBL1a encoding gene were developed for its functional validation through an efficient Agrobacterium-mediated in-planta transformation method. This study expounds a highly efficient method for rice transformation. OsRuvBL1a interacts with different proteins which directly or indirectly are involved in providing stress tolerance to the plant as shown in working mechanism (Fig. 7). Multiple physiological and biochemical analysis showed the better performance of OsRuvBL1a overexpressing transgenic lines under salinity and drought stress as compared to WT plants. This is the first report that details the role of RuvBL1 in plants and the information of its characteristics, highlighted through the present study, lays the foundation for the potential use of this enzyme in crop improvement. Furthermore, its role in mitigating the negative effects of abiotic stress in plants indicate its potential use in engineering plants for overcoming abiotic stress.

\section{Declarations:}

\section{Conflict of interest}

We do not have any conflict of interest to declare.

\section{Author Contribution Statement}

SKS and NP conducted the experiment, NT and MN designed the study and SSG help in writing the manuscript. RT and NT thoroughly reviewed the manuscript.

\section{Acknowledgements}

SKS acknowledges CSIR and NP acknowledges DBT India for providing the fellowship.

\section{References:}

1. Abrahao $\mathrm{J}$ et al (2021) Leishmania major RUVBL1 has a hexameric conformation in solution and in the presence of RUVBL2, forms a heterodimer with ATPase activity Archives of biochemistry and biophysics:108841 doi:10.1016/j.abb.2021.108841 
2. Ahmad M, Tuteja R (2012) Plasmodium falciparum RuvB proteins. Communicative Integrative Biology 5:350-361. doi:10.4161/cib.20005

3. Antony JJJ, Keng CL, Rathinam X, Sinniah UR, Subramaniam S (2015) Preliminary study on cryopreservation of Dendrobium Bobby Messina protocorm-like bodies by vitrification African. $J$ Biotechnol 9:7063-7070

4. Bent AF (2000) Arabidopsis in planta transformation. Uses, mechanisms, and prospects for transformation of other species. Plant Physiol 124:1540-1547

5. Blumwald E (2000) Sodium transport and salt tolerance in plants Current opinion in cell biology 12:431-434 doi:10.1016/s0955-0674(00)00112-5

6. Chen Y, Wang XM, Zhou L, He Y, Wang D, Qi YH, Jiang DA (2015) Rubisco Activase Is Also a Multiple Responder to Abiotic Stresses in. Rice PLoS One 10:e0140934. doi:10.1371/journal.pone.0140934

7. Cheung KL, Huen J, Kakihara Y, Houry WA, Ortega J (2010) Alternative oligomeric states of the yeast Rvb1/Rvb2 complex induced by histidine tags. J Mol Biol 404:478-492. doi:10.1016/j.jmb.2010.10.003

8. Cho YH, Yoo SD (2014) Novel connections and gaps in ethylene signaling from the ER membrane to the nucleus. Front Plant Sci 5:733. doi:10.3389/fpls.2014.00733

9. Collins T (2007) ImageJ for microscopy BioTechniques 43:S25-S30 doi:10.2144/000112517

10. Dang HQ, Tran NQ, Gill SS, Tuteja R, Tuteja N (2011) A single subunit MCM6 from pea promotes salinity stress tolerance without affecting yield. Plant molecular biology 76:19-34. doi:10.1007/s11103-011-9758-0

11. DeYoung BJ, Innes RW (2006) Plant NBS-LRR proteins in pathogen sensing and host defense. Nature immunology 7:1243-1249. doi:10.1038/ni1410

12. Dixon DP, Hawkins T, Hussey PJ, Edwards R (2009) Enzyme activities and subcellular localization of members of the Arabidopsis glutathione transferase superfamily. J Exp Bot 60:1207-1218. doi:10.1093/jxb/ern365

13. Dong J, Kharb P, Cervera M, Hall TC (2001) The use of FISH in chromosomal localization of transgenes in rice. Methods Cell Sci 23:105-113

14. Edgerton MD (2009) Increasing crop productivity to meet global needs for feed, food, and fuel. Plant Physiol 149:7-13. doi:10.1104/pp.108.130195

15. Flowers TJ, Colmer TD (2008) Salinity tolerance in halophytes*. New Phytol 179:945-963. doi:10.1111/j.1469-8137.2008.02531.x

16. Fukui K (1983) Sequential occurrence of mutations in a growing rice callus TAG Theoretical and applied genetics Theoretische. und angewandte Genetik 65:225-230. doi:10.1007/BF00308073

17. Furstenberg-Hagg J, Zagrobelny M, Bak S (2013) Plant defense against insect herbivores. Int J Mol Sci 14:10242-10297. doi:10.3390/ijms140510242

18. Gao J, Lan T (2016) Functional characterization of the late embryogenesis abundant (LEA) protein gene family from Pinus tabuliformis (Pinaceae) in Escherichia coli. Sci Rep 6:19467. 
doi:10.1038/srep19467

19. Garg B, Jaiswal JP, Misra S, Tripathi BN, Prasad M (2012) A comprehensive study on dehydrationinduced antioxidative responses during germination of Indian bread wheat (Triticum aestivum L. em Thell) cultivars collected from different agroclimatic zones Physiology and molecular biology of plants: an. international journal of functional plant biology 18:217-228. doi:10.1007/s12298-0120117-7

20. Gill SS, Tuteja N (2010) Reactive oxygen species and antioxidant machinery in abiotic stress tolerance in crop plants. Plant Physiol Biochem 48:909-930. doi:10.1016/j.plaphy.2010.08.016

21. Godfray HC et al (2010) Food security: the challenge of feeding 9. billion people Science 327:812818. doi:10.1126/science. 1185383

22. Gordon-Kamm W et al (2002) Stimulation of the cell cycle and maize transformation by disruption of the plant retinoblastoma pathway Proceedings of the National Academy of Sciences 99:1197511980 doi:10.1073/pnas.142409899

23. Gorynia S et al (2011) Structural and functional insights into a dodecameric molecular machine - the RuvBL1/RuvBL2 complex. J Struct Biol 176:279-291. doi:10.1016/j.jsb.2011.09.001

24. Gribun A, Cheung KL, Huen J, Ortega J, Houry WA (2008) Yeast Rvb1 and Rvb2 are ATP-dependent DNA helicases that form a heterohexameric complex. J Mol Biol 376:1320-1333. doi:10.1016/j.jmb.2007.12.049

25. Hansen G, Wright MS (1999) Recent advances in the transformation of plants. Trends Plant Sci $4: 226-231$

26. Hiei Y, Ishida Y, Kasaoka K, Komari T (2006) Improved frequency of transformation in rice and maize by treatment of immature embryos with centrifugation and heat prior to infection with Agrobacterium tumefaciens Plant Cell. Tissue Organ Culture 87:233-243. doi:10.1007/s11240-006-9157-4

27. Holt BF 3rd et al (2002) An evolutionarily conserved mediator of plant disease resistance gene function is required for normal Arabidopsis. development Dev Cell 2:807-817

28. Hosein FN, Lennon AM, Umaharan P (2012) Optimization of an Agrobacterium-mediated transient assay for gene expression studies in Anthurium andraeanum. J Am Soc Hortic Sci 137:263-272

29. Huang L, Hong Y, Zhang H, Li D, Song F (2016) Rice NAC transcription factor ONAC095 plays opposite roles in drought and cold stress tolerance. BMC plant biology 16:203. doi:10.1186/s12870016-0897-y

30. Huang X, Wei Z (2005) Successful Agrobacterium-Mediated Genetic Transformation of Maize Elite Inbred lines. Plant Cell Tiss Organ Cult 83:187-200. doi:10.1007/s11240-005-5772-8

31. Hubbard KE, Nishimura N, Hitomi K, Getzoff ED, Schroeder JI (2010) Early abscisic acid signal transduction mechanisms: newly discovered components and newly emerging questions. Genes Dev 24:1695-1708. doi:10.1101/gad.1953910

32. Huda KM, Banu MS, Garg B, Tula S, Tuteja R, Tuteja N (2013) OsACA6, a P-type IIB Ca(2)(+) ATPase promotes salinity and drought stress tolerance in tobacco by ROS scavenging and enhancing the 
expression of stress-responsive genes The Plant journal. for cell molecular biology 76:997-1015. doi:10.1111/tpj.12352

33. Ishiga Y, Ishiga T, Uppalapati SR, Mysore KS (2013) Jasmonate ZIM-domain (JAZ) protein regulates host and nonhost pathogen-induced cell death in tomato and Nicotiana benthamiana. PloS one 8:e75728. doi:10.1371/journal.pone.0075728

34. Jeganathan A, Leong V, Zhao L, Huen J, Nano N, Houry WA, Ortega J (2015) Yeast rvb1 and rvb2 proteins oligomerize as a conformationally variable dodecamer with low frequency. J Mol Biol 427:1875-1886. doi:10.1016/j.jmb.2015.01.010

35. Jin J et al (2005) A mammalian chromatin remodeling complex with similarities to the yeast INO80 complex. J Biol Chem 280:41207-41212. doi:10.1074/jbc.M509128200

36. Jonsson ZO et al (2001) Rvb1p and Rvb2p Are Essential Components of a Chromatin Remodeling Complex That Regulates Transcription of over $5 \%$ of Yeast Genes. J Biol Chem 276:16279-16288. doi:10.1074/jbc.m011523200

37. Kanemaki $\mathrm{M}$ et al (1997) Molecular Cloning of a Rat 49-kDa TBP-Interacting Protein (TIP49) That Is Highly Homologous to the Bacterial RuvB Biochemical and. Biophysical Research Communications 235:64-68. doi:10.1006/bbrc.1997.6729

38. Kappachery S, Baniekal-Hiremath G, Yu JW, Park SW (2014) Effect of over-and under-expression of glyceraldehyde 3-phosphate dehydrogenase on tolerance of plants to water-deficit stress Plant Cell. Tissue Organ Culture (PCTOC) 121:97-107. doi:10.1007/s11240-014-0684-0

39. Kavitha PG, Miller AJ, Mathew MK, Maathuis FJM (2012) Rice cultivars with differing salt tolerance contain similar cation channels in their root cells. J Exp Bot 63:3289-3296. doi:10.1093/jxb/ers052

40. Keown JR, Griffin MD, Mertens HD, Pearce FG (2013) Small oligomers of ribulose-bisphosphate carboxylase/oxygenase (Rubisco) activase are required for biological activity. J Biol Chem 288:20607-20615. doi:10.1074/jbc.M113.466383

41. Keshamma E et al (2011) Agrobacterium-Mediated In Planta Transformation of Field Bean (Lablab purpureus L.) and Recovery of Stable Transgenic Plants Expressing the cry1AcF Gene. Plant Molecular Biology Reporter 30:67-78. doi:10.1007/s11105-011-0312-7

42. Khan MS, Hemalatha S (2016) Biochemical and molecular changes induced by salinity stress in Oryza sativa L Acta Physiologiae Plantarum 38 doi:10.1007/s11738-016-2185-8

43. Klingler JP, Batelli G, Zhu JK (2010) ABA receptors: the START of a new paradigm in phytohormone signalling. J Exp Bot 61:3199-3210. doi:10.1093/jxb/erq151

44. Kumar RR et al (2016) Identification of Putative RuBisCo Activase (TaRca1)-The Catalytic Chaperone Regulating Carbon Assimilatory Pathway in Wheat (Triticum aestivum) under the Heat Stress. Front Plant Sci 7:986. doi:10.3389/fpls.2016.00986

45. Kumlehn J, Serazetdinova L, Hensel G, Becker D, Loerz H (2006) Genetic transformation of barley (Hordeum vulgare L.) via infection of androgenetic pollen cultures with Agrobacterium tumefaciens. Plant Biotechnol J 4:251-261. doi:10.1111/j.1467-7652.2005.00178.x 
46. Lin J, Zhang W, Shi M, Wang X, Sun X, Tang K (2008) Isolation and molecular characterization of a cax gene from Capsella bursa-pastoris Biocell: official journal of the Sociedades Latinoamericanas de Microscopia Electronica et al 32:229-235

47. Lin $J$ et al (2009) Piercing and vacuum infiltration of the mature embryo: a simplified method for Agrobacterium-mediated transformation of indica rice. Plant Cell Rep 28:1065-1074. doi:10.1007/s00299-009-0706-2

48. Liu X, Inoue H, Tang X, Tan Y, Xu X, Wang C, Jiang CJ (2020) Rice OsAAA-ATPase1 is Induced during Blast Infection in a Salicylic Acid-Dependent Manner, and Promotes Blast Fungus Resistance International journal of molecular sciences 21 doi:10.3390/ijms21041443

49. Liu Y, Koornneef M, Soppe WJJ (2007) The Absence of Histone H2B Monoubiquitination in the Arabidopsis hub1 (rdo4) Mutant Reveals a Role for Chromatin Remodeling in Seed Dormancy THE PLANT CELL. ONLINE 19:433-444. doi:10.1105/tpc.106.049221

50. Lupas AN, Martin J (2002) AAA proteins Current opinion in structural biology 12:746-753

51. Mao X, Zhang H, Qian X, Li A, Zhao G, Jing R (2012) TaNAC2, a NAC-type wheat transcription factor conferring enhanced multiple abiotic stress tolerances in Arabidopsis. J Exp Bot 63:2933-2946. doi:10.1093/jxb/err462

52. Mariashibu TS et al (2013) Assessment of somatic embryogenesis potency in Indian soybean [Glycine max (L.) Merr.] cultivars. Indian journal of experimental biology 51:849-859

53. Marone D, Russo MA, Laido G, De Leonardis AM, Mastrangelo AM (2013) Plant nucleotide binding site-leucine-rich repeat (NBS-LRR) genes: active guardians in host defense responses. Int J Mol Sci 14:7302-7326. doi:10.3390/ijms14047302

54. Mayavan S et al (2013) Agrobacterium tumefaciens-mediated in planta seed transformation strategy in sugarcane. Plant cell reports 32:1557-1574. doi:10.1007/s00299-013-1467-5

55. McCormac AC, Wu H, Bao M, Wang Y, Xu R, Elliott MC, Chen D-F (1998) The use of visual marker genes as cell-specific reporters of Agrobacterium-mediated T-DNA delivery to wheat (Triticum aestivum L.) and barley (Hordeum vulgare L.). Euphytica 99:17-25. doi:10.1023/A:1018303102488

56. McHale L, Tan X, Koehl P, Michelmore RW (2006) Plant NBS-LRR proteins: adaptable guards Genome biology 7:212 doi:10.1186/gb-2006-7-4-212

57. Morrison AJ, Shen X (2009) Chromatin remodelling beyond transcription: the INO80 and SWR1 complexes. Nat Rev Mol Cell Biol 10:373-384. doi:10.1038/nrm2693

58. Munns R (2002) Comparative physiology of salt and water stress Plant. Cell Environment 25:239250. doi:10.1046/j.0016-8025.2001.00808.x

59. Nath M, Garg B, Sahoo RK, Tuteja N (2015) PDH45 overexpressing transgenic tobacco and rice plants provide salinity stress tolerance via less sodium accumulation. Plant Signal Behav 10:e992289. doi:10.4161/15592324.2014.992289

60. Nath M, Yadav S, Kumar Sahoo R, Passricha N, Tuteja R, Tuteja N (2016) PDH45 transgenic rice maintain cell viability through lower accumulation of $\mathrm{Na}(+), \mathrm{ROS}$ and calcium homeostasis in roots under salinity stress. J Plant Physiol 191:1-11. doi:10.1016/j.jplph.2015.11.008 
61. Niewiarowski A, Bradley AS, Gor J, McKay AR, Perkins SJ, Tsaneva IR (2010) Oligomeric assembly and interactions within the human RuvB-like RuvBL1 and RuvBL2 complexes. Biochem J 429:113125. doi:10.1042/BJ20100489

62. Nishimura A, Ashikari M, Lin S, Takashi T, Angeles ER, Yamamoto T, Matsuoka M (2005) Isolation of a rice regeneration quantitative trait loci gene and its application to transformation systems Proceedings of the National Academy of Sciences 102:11940-11944 doi:10.1073/pnas.0504220102

63. Ortega-Amaro MA et al (2014) Overexpression of AtGRDP2, a novel glycine-rich domain protein, accelerates plant growth and improves stress tolerance. Front Plant Sci 5:782. doi:10.3389/fpls.2014.00782

64. Passricha N, Behl RK, Sikka VK (2014) AGPase: An Allegiance To Food Security. In: R.K. Behl ARAWM (ed). pp 81-88

65. Passricha N, Saifi S, Khatodia S, Tuteja N (2016) Assessing zygosity in progeny of transgenic plants: current methods and perspectives Journal of Biological Methods; Vol 3, No 3 (2016)

66. Passricha N, Saifi SK, Gill SS, Tuteja R, Tuteja N (2019a) Chap. 3 - Role of Plant Helicases in Imparting Salinity Stress Tolerance to Plants. In: Tuteja R (ed) Helicases from All Domains of Life. Academic Press, pp 39-52. doi:https://doi.org/10.1016/B978-0-12-814685-9.00003-8

67. Passricha N, Saifi SK, Kharb P, Tuteja N (2019b) Marker-free transgenic rice plant overexpressing pea LecRLK imparts salinity tolerance by inhibiting sodium accumulation Plant Molecular Biology doi:10.1007/s11103-018-0816-8

68. Passricha N, Saifi SK, Kharb P, Tuteja N (2020) Rice lectin receptor-like kinase provides salinity tolerance by ion homeostasis. Biotechnol Bioeng 117:498-510. doi:10.1002/bit.27216

69. Ra C, He S, Mk M (2016) Analysis of Morphological and Physiological Responses to Drought and Salinity in Four Rice (Oryza sativa L.) Varieties Agrotechnology 05 doi:10.4172/2168-9881.1000151

70. Rahman H, Ramanathan V, Nallathambi J, Duraialagaraja S, Muthurajan R (2016) Over-expression of a NAC 67 transcription factor from finger millet (Eleusine coracana L.) confers tolerance against salinity and drought stress in rice BMC biotechnology 16 Suppl 1:35 doi:10.1186/s12896-016-0261-1

71. Rai MK, Shekhawat NS, Harish, Gupta AK, Phulwaria M, Ram K, Jaiswal U (2011) The role of abscisic acid in plant tissue culture: a review of recent progress. Plant Cell Tiss Organ Cult 106:179-190. doi:10.1007/s11240-011-9923-9

72. Ratanasut K, Rod-In W, Sujipuli K (2017) In planta Agrobacterium -Mediated Transformation of. Rice Rice Science 24:181-186. doi:10.1016/j.rsci.2016.11.001

73. Raza H (2011) Dual localization of glutathione S-transferase in the cytosol and mitochondria: implications in oxidative stress. toxicity disease The FEBS journal 278:4243-4251. doi:10.1111/j.1742-4658.2011.08358.x

74. Sahoo RK, Tuteja N (2012) Development of Agrobacterium-mediated transformation technology for mature seed-derived callus tissues of indica rice cultivar IR64 GM crops \&. food 3:123-128. doi:10.4161/gmcr.20032 
75. Saifi SK, Passricha N, Tuteja R, Tuteja N (2018) Stress-induced Oryza sativa RuvBL1a is DNAindependent ATPase and unwinds DNA duplex in 3' to 5' direction Protoplasma doi:10.1007/s00709017-1178-9

76. Saifı SK, Passricha N, Tuteja R, Tuteja N (2019) Chap. 14 - An Overview of AAA + Superfamily Proteins Associated Helicases. In: Tuteja R (ed) Helicases from All Domains of Life. Academic Press, pp 247-264. doi:https://doi.org/10.1016/B978-0-12-814685-9.00015-4

77. Sajib AA, Shahidul Islam M, Shamim Reza M, Bhowmik A, Fatema L, Khan H (2008) Tissue culture independent transformation for Corchorus olitorius. Plant Cell Tiss Organ Cult 95:333-340. doi:10.1007/s11240-008-9447-0

78. Sangwan RS, Bourgeois Y, Sangwan-Norreel BS (1991) Genetic transformation of Arabidopsis thaliana zygotic embryos and identification of critical parameters influencing transformation efficiency. Mol Gen Genet 230:475-485

79. Schorova S, Fajkus J, Zaveska Drabkova L, Honys D, Schrumpfova PP (2019) The plant Pontin and Reptin homologues, RuvBL1 and RuvBL2a, colocalize with TERT and TRB proteins in vivo, and participate in telomerase biogenesis The Plant journal: for. cell molecular biology 98:195-212. doi:10.1111/tpj.14306

80. Sewelam N, Kazan K, Schenk PM (2016) Global Plant Stress Signaling: Reactive Oxygen Species at the Cross-Road. Front Plant Sci 7:187. doi:10.3389/fpls.2016.00187

81. Shimada A et al (2006) The rice SPINDLY gene functions as a negative regulator of gibberellin signaling by controlling the suppressive function of the DELLA protein, SLR1, and modulating brassinosteroid synthesis The Plant journal: for cell. and molecular biology 48:390-402. doi:10.1111/j.1365-313X.2006.02875.x

82. Shivakumara TN et al (2017) Overexpression of Pea DNA Helicase 45 (PDH45) imparts tolerance to multiple abiotic stresses in chili (Capsicum annuum L.). Scientific reports 7:2760. doi:10.1038/s41598-017-02589-0

83. Sigala B, Edwards M, Puri T, Tsaneva IR (2005) Relocalization of human chromatin remodeling cofactor TIP48 in mitosis. Exp Cell Res 310:357-369. doi:10.1016/j.yexcr.2005.07.030

84. Singleton MR, Dillingham MS, Wigley DB (2007) Structure and mechanism of helicases and nucleic acid translocases. Annual review of biochemistry 76:23-50.

doi:10.1146/annurev.biochem.76.052305.115300

85. Smulders MJM, de Klerk GJ (2010) Epigenetics in plant tissue culture. Plant Growth Regul 63:137146. doi:10.1007/s10725-010-9531-4

86. Snider J, Thibault G, Houry WA (2008) The AAA + superfamily of functionally diverse proteins. Genome biology 9:216. doi:10.1186/gb-2008-9-4-216

87. Song $\mathrm{H}$ et al (2017) Comparative analysis of NBS-LRR genes and their response to Aspergillus flavus in Arachis. PloS one 12:e0171181. doi:10.1371/journal.pone.0171181

88. Subramanyam K et al (2013) Assessment of Factors Influencing the Agrobacterium-mediated in planta Seed Transformation of Brinjal (Solanum melongena L.). Appl Biochem Biotechnol 171:450- 
468. doi:10.1007/s12010-013-0359-z

89. Supartana P, Shimizu T, Shioiri H, Nogawa M, Nozue M, Kojima M (2005) Development of simple and efficient in planta transformation method for rice (Oryza sativa L.) using Agrobacterium tumefaciens. J Biosci Bioeng 100:391-397. doi:10.1263/jbb.100.391

90. Tu Y et al (2014) Genome duplication improves rice root resistance to salt. stress Rice 7:15. doi:10.1186/s12284-014-0015-4

91. Tuteja N, Banu MS, Huda KM, Gill SS, Jain P, Pham XH, Tuteja R (2014) Pea p68, a DEAD-box helicase, provides salinity stress tolerance in transgenic tobacco by reducing oxidative stress and improving photosynthesis machinery. PLoS One 9:e98287. doi:10.1371/journal.pone.0098287

92. Tuteja N, Sahoo RK, Garg B, Tuteja R (2013) OsSUV3 dual helicase functions in salinity stress tolerance by maintaining photosynthesis and antioxidant machinery in rice (Oryza sativa L. cv. IR64). The Plant journal: for cell molecular biology 76:115-127. doi:10.1111/tpj.12277

93. Tuteja N, Tarique M, Trivedi DK, Sahoo RK, Tuteja R (2015) Stress-induced Oryza sativa BAT1 dual helicase exhibits unique. bipolar translocation Protoplasma 252:1563-1574. doi:10.1007/s00709015-0791-8

94. Tuteja N, Verma S, Sahoo RK, Raveendar S, Reddy IN (2012) Recent advances in development of marker-free transgenic plants: regulation and biosafety concern. J Biosci 37:167-197

95. Vieira AR, Vieira MdGGC, Fraga AC, Oliveira JA, Santos CDd (2002) Action of gibberellic acid (GA3) on dormancy and activity of alpha-amylase in rice seeds. Revista Brasileira de Sementes 24:43-48. doi:10.1590/s0101-31222002000100008

96. Villemont E, Dubois Fdr, Sangwan RS, Vasseur Gr, Bourgeois Y, Sangwan-Norreel BS (1997) Role of the host cell cycle in theAgrobacterium-mediated genetic transformation ofPetunia: Evidence of an Sphase control mechanism for T. -DNA transfer Planta 201:160-172. doi:10.1007/bf01007700

97. Vitamvas P, Prasil IT, Kosova K, Planchon S, Renaut J (2012) Analysis of proteome and frost tolerance in chromosome $5 \mathrm{~A}$ and $5 \mathrm{~B}$ reciprocal substitution lines between two winter wheats during long-term. cold acclimation Proteomics 12:68-85. doi:10.1002/pmic.201000779

98. Vitha S, Benes K, Phillips JP, Gartland KM (1995) Histochemical GUS analysis Methods. in molecular biology 44:185-193. doi:10.1385/0-89603-302-3:185

99. Wang CW, Chen WC, Lin LJ, Lee CT, Tseng TH, Leu WM (2011) OIP30, a RuvB-Like DNA Helicase 2, is a Potential Substrate for the Pollen-Predominant OsCPK25/26 in Rice Plant. and Cell Physiology 52:1641-1656. doi:10.1093/pcp/pcr094

100. Wang G, Kong F, Zhang S, Meng X, Wang Y, Meng Q (2015) A tomato chloroplast-targeted DnaJ protein protects Rubisco activity under heat stress. J Exp Bot 66:3027-3040. doi:10.1093/jxb/erv102

101. Wang L, Xu C, Wang C, Wang Y (2012) Characterization of a eukaryotic translation initiation factor $5 \mathrm{~A}$ homolog from Tamarix androssowii involved in plant abiotic stress tolerance. BMC plant biology 12:118. doi:10.1186/1471-2229-12-118

102. Wang $Y$ et al (2017) Genome-wide characterization of JASMONATE-ZIM DOMAIN transcription repressors in wheat (Triticum aestivum L.). BMC Genom 18:152. doi:10.1186/s12864-017-3582-0 
103. Winans SC, Kerstetter RA, Nester EW (1988) Transcriptional regulation of the virA and virG genes of Agrobacterium tumefaciens. J Bacteriol 170:4047-4054

104. Wong-Ekkabut J, Xu Z, Triampo W, Tang IM, Tieleman DP, Monticelli L (2007) Effect of lipid peroxidation on the properties of lipid bilayers: a molecular dynamics study. Biophysical journal 93:4225-4236. doi:10.1529/biophysj.107.112565

105. Wood MA, McMahon SB, Cole MD (2000) An ATPase/Helicase Complex Is an Essential Cofactor for Oncogenic Transformation by c-Myc. Mol Cell 5:321-330. doi:10.1016/s1097-2765(00)80427-x

106. Yadav $S$ et al (2018) Genome-wide analysis and transcriptional expression pattern-assessment of superoxide dismutase (SOD) in rice and Arabidopsis under abiotic stresses Plant Gene doi:https://doi.org/10.1016/j.plgene.2018.10.001

107. Yang CH, Yang PC, Li J, Yang F, Zhang AB (2016) Transcriptome Characterization of Dendrolimus punctatus and Expression Profiles at Different Developmental Stages PloS one 11:e0161667 doi:10.1371/journal.pone.0161667

108. Yao LM, Jiang YN, Lu XX, Wang B, Zhou P, Wu TL (2016) Overexpression of a glycine-rich protein gene in Lablab purpureus improves abiotic stress tolerance Genetics and molecular research. GMR 15. doi:10.4238/gmr15048063

109. Zhang J, Li J, Wang X, Chen J (2011) OVP1, a Vacuolar H+-translocating inorganic pyrophosphatase (V-PPase), overexpression improved rice cold tolerance. Plant Physiol Biochem 49:33-38. doi:10.1016/j.plaphy.2010.09.014

110. Zhang Y, Liu J, Chai J, Xing D (2016) Mitogen-activated protein kinase 6 mediates nuclear translocation of ORE3 to promote ORE9 gene expression in methyl jasmonate-induced leaf senescence. J Exp Bot 67:83-94. doi:10.1093/jxb/erv438

111. Zhao R et al (2008) Molecular chaperone Hsp90 stabilizes Pih1/Nop17 to maintain R2TP complex activity that regulates snoRNA. accumulation The Journal of Cell Biology 180:563-578. doi:10.1083/jcb.200709061

112. Zhao Z, Zhang W, Yan J, Zhang J, Liu ZLX, Yi Y (2010) Over-expression of Arabidopsis DnaJ (Hsp40) contributes to $\mathrm{NaCl}$-stress tolerance African. J Biotechnol 9:972-978. doi:10.5897/ajb09.1450

113. Zhou HP et al (2003) Agrobacterium-mediated large-scale transformation of wheat (Triticum aestivum L.) using glyphosate selection. Plant cell reports 21:1010-1019. doi:10.1007/s00299-0030617-6

\section{Figures}



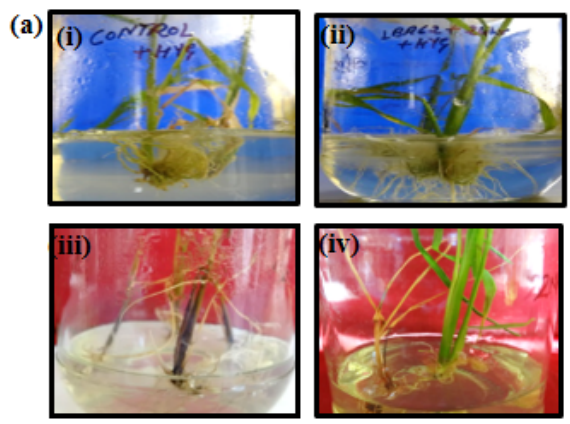

(b)

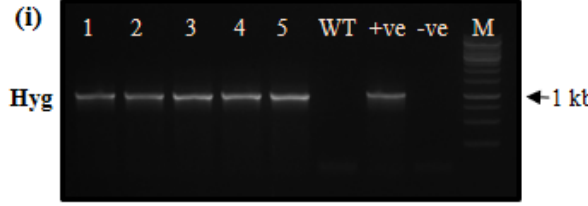

(ii)
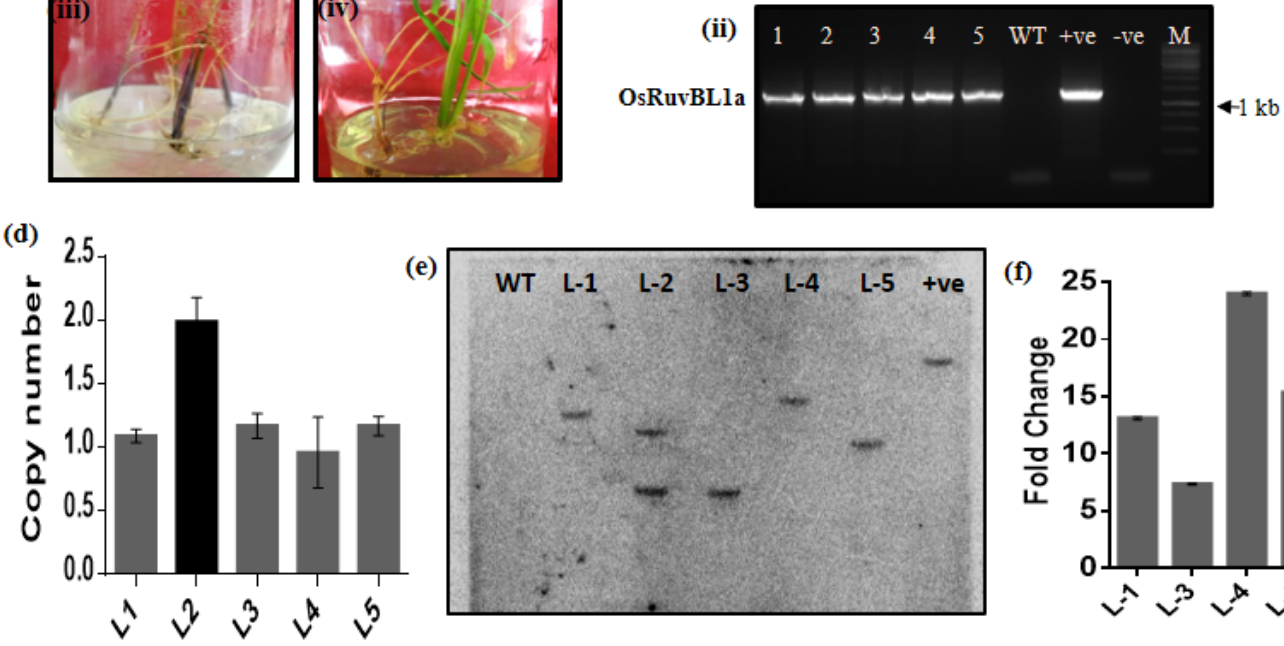

(e)
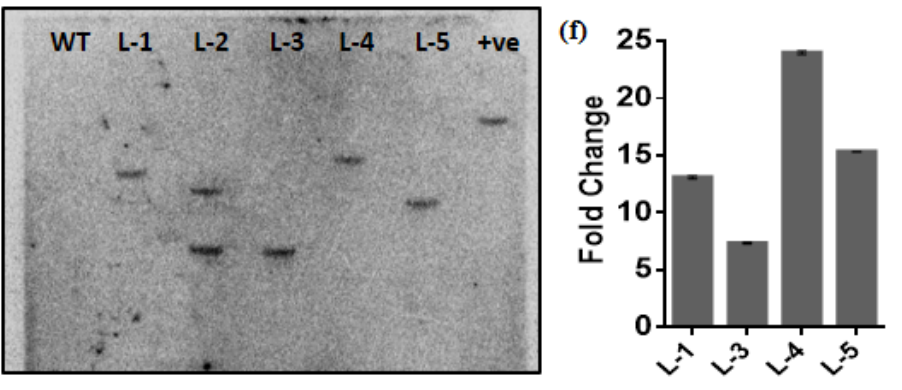

(h)

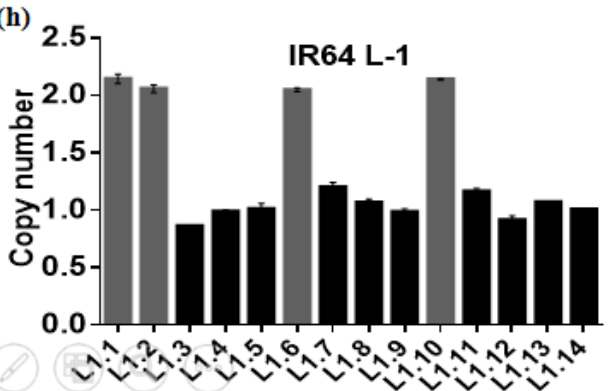

(i) 2.5 IR64 L-4

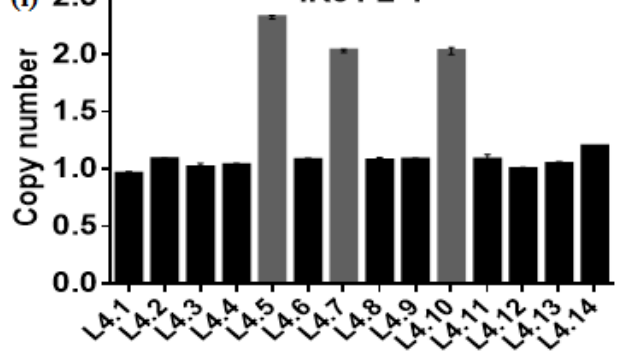

(g)

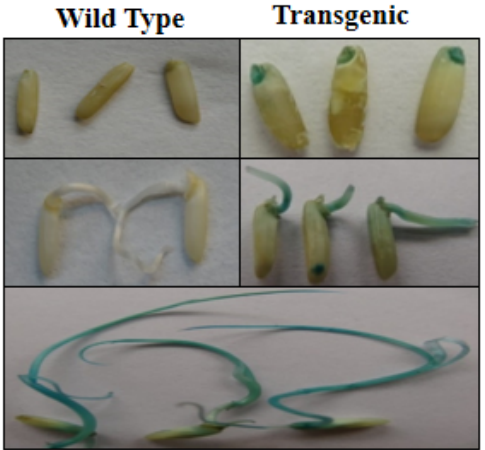

(c)

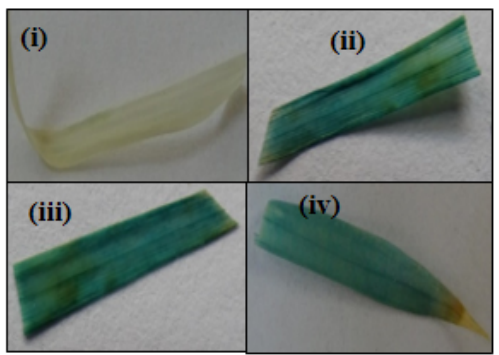

(j) 2.5

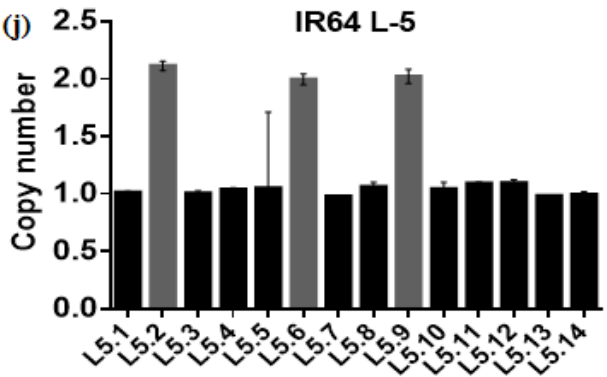

\section{Figure 1}

Biochemical characterization of OsRuvBL1 (a) SDS-PAGE of purified OsRuvBL1a. (b) Western blot analysis of purified OsRuvBL1a (Lane 1-purified protein and M-protein marker). (c) ATPase assay of OsRuvBL1a in absence of nucleic acid (C- control). (d) ATPase assay of OsRuvBL1a in presence of ssDNA (C-control). (e) Helicase activity of OsRuvBL1a (Lanes C- negative control without protein, B-boiled substrate). 
(a)
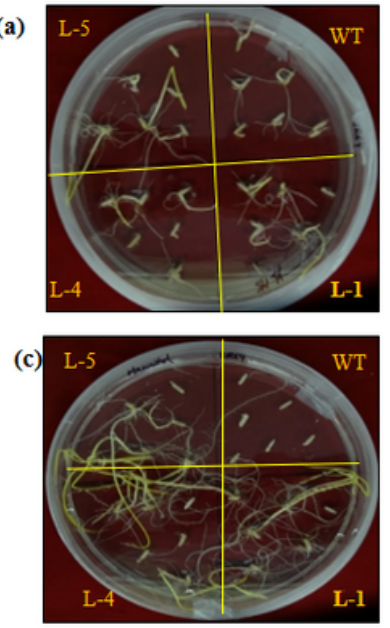

(e)

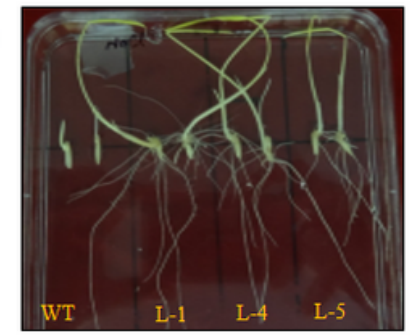

(b)
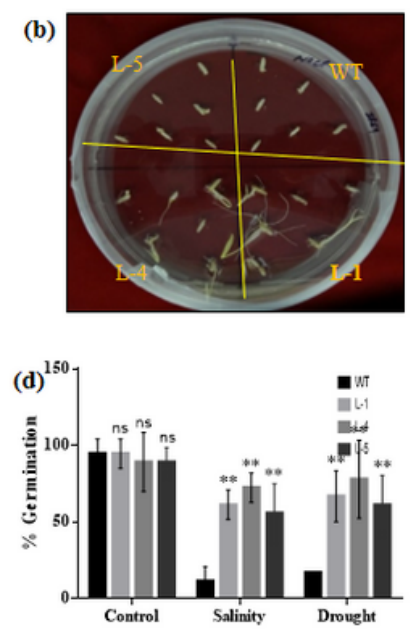

(f)

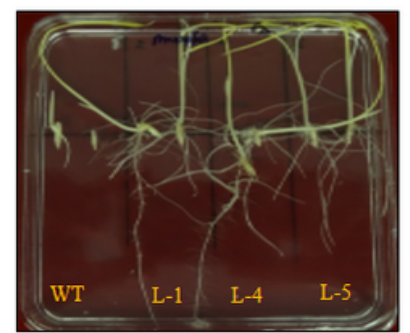

(i)

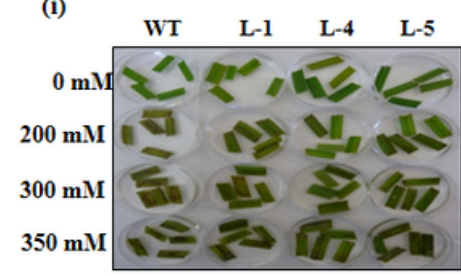

(k)
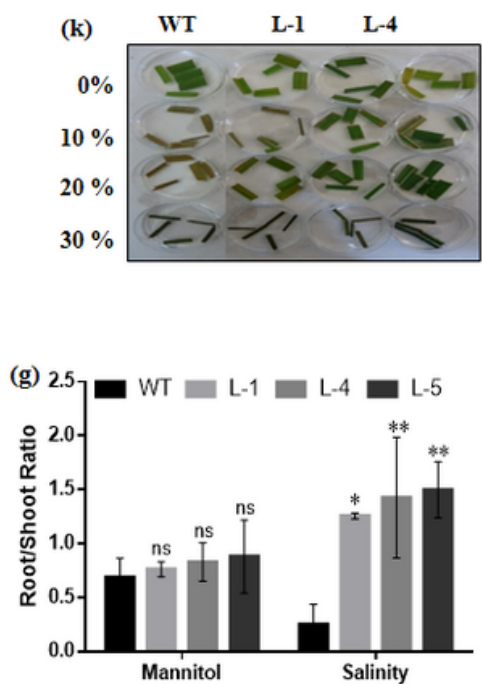

(j)
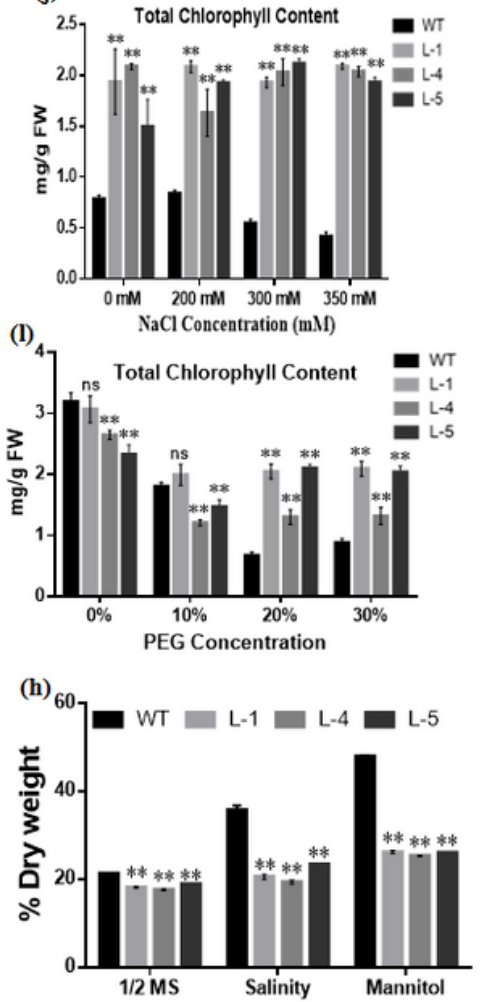

Figure 2

In-planta rice transformation for overexpression of OsRuvBL1a (a) Putative transgenic plants showed survival on hygromycin supplemented media and WT plant showed death (i and iii) and transgenic lines survived (ii and iv) under hygromycin selection. (b) PCR selection of transgenic plants (i) with hygromycin $\mathrm{F}^{\prime}$ and $\mathrm{R}^{\prime}$ primers showing $1 \mathrm{~kb}$ amplicon (ii) with CaMV35S F' and OsRuvBL1a R' primers showing 1.4 kb amplicon. (c) GUS analysis of transgenic plants at T0 stage (i) WT plant as control and (ii-iv) transgenic plants showed positive GUS assay. (d) Copy number analysis with real-time method showed lines L-1, 3, 4 and 5 with single site insertion and L-2 with double insertion site. (e) Southern blot hybridization showed lines L-1, 3, 4 and 5 with single site insertion. (f) qPCR based transcript level analysis in OsRuvBL1a overexpressing transgenic lines for lines L-1, 3, 4 and 5. (g) Color formation in GUS analysis of T1 generation at different stages of seed germination. (h-j) Homozygous plants in lines L-1, 4 and 5 . 

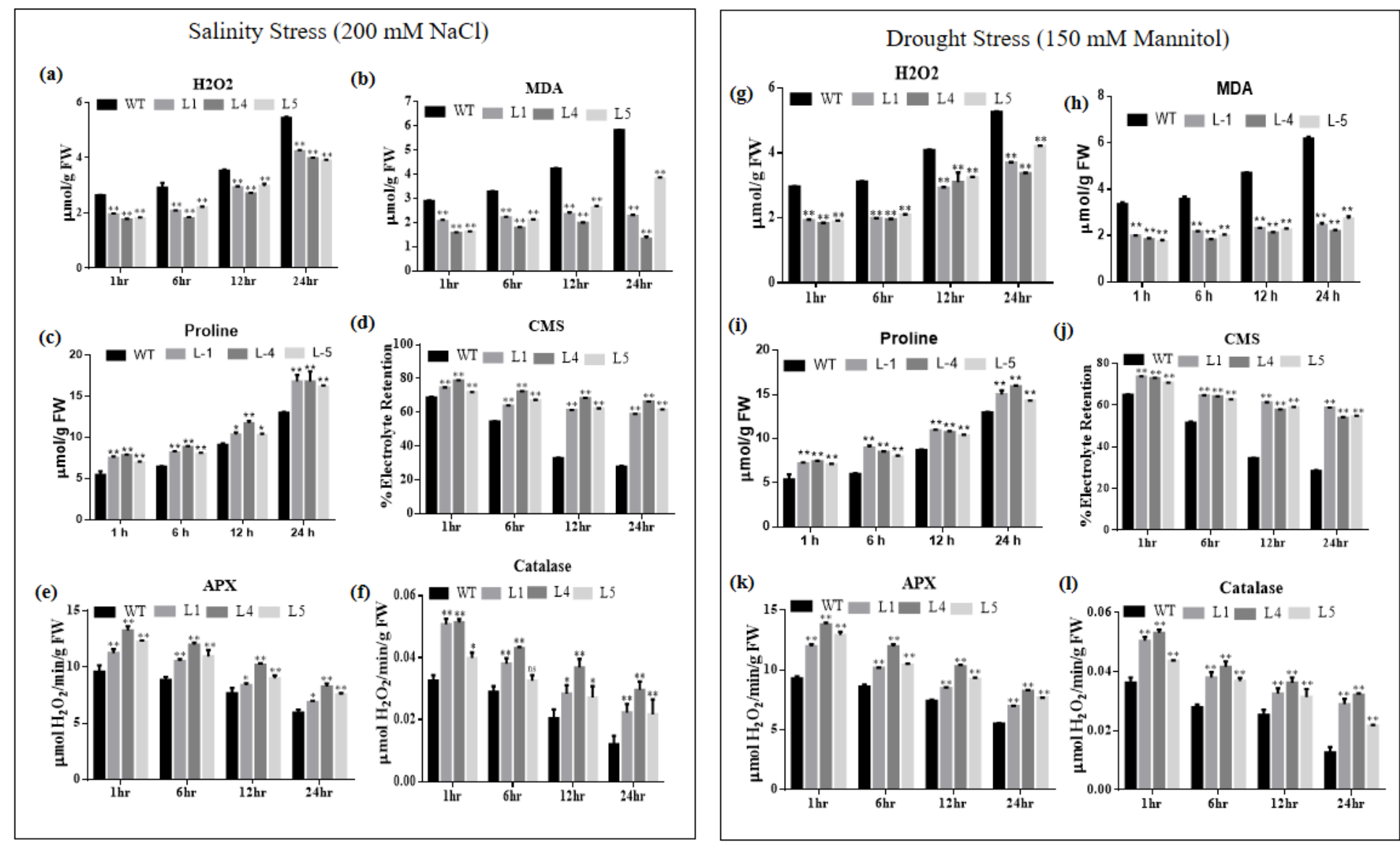

Figure 3

Physiological analysis of OsRuvBL1a overexpression transgenic lines under salinity and drought stress conditions (a-c) Germination assay of OsRuvBL1a overexpression transgenic lines L-1, L-4 and L-5 with respect to WT under salinity and drought stress conditions (a) on $1 / 2 \mathrm{MS}$ (control) (b) on $200 \mathrm{mM} \mathrm{NaCl}$ and (c) on $150 \mathrm{mM}$ mannitol (d) Germination percentage analysis of WT and transgenic lines under salinity and drought stress. (e-g) Root-shoot length and ratio analysis of WT and transgenic lines under salinity (200 mM NaCl) and drought (150 mM mannitol) stress. (h) Dry weight analysis of WT and transgenic lines under control, salinity and drought conditions. (i-j) Chlorophyll estimation of WT and OsRuvBL1a transgenic lines under salinity conditions $(200,300$ and $350 \mathrm{mM} \mathrm{NaCl})$. (k-l) Chlorophyll estimation of WT and OsRuvBL1a overexpressing transgenic lines under drought conditions (10\%, $20 \%$ and $30 \%$ PEG). The significant difference between the mean values $(n=3)$ of WT and OsRuvBL1a overexpressing transgenic lines (L1, 4 and 5) were determined by analysis of variance (ANOVA) using Graphpad PRISM. The statistical significance was represented as " " and " $\star \star$ " for $p<0.05$ and $p<0.01$ respectively. 
(a)

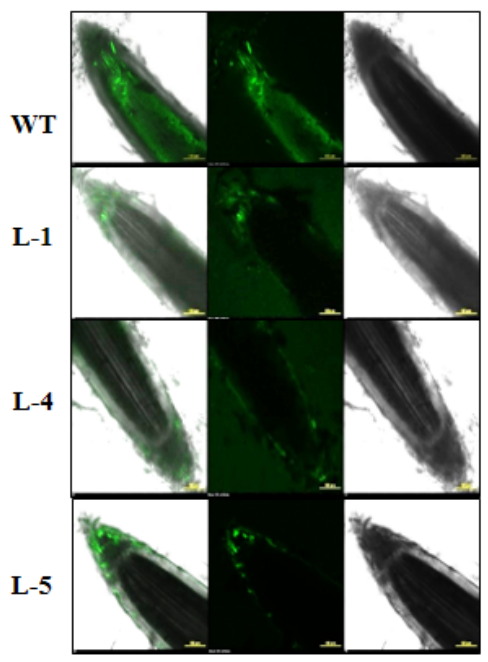

(b)

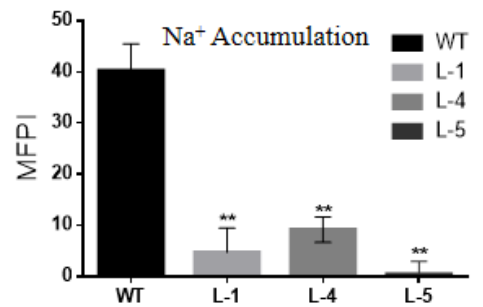

(c)

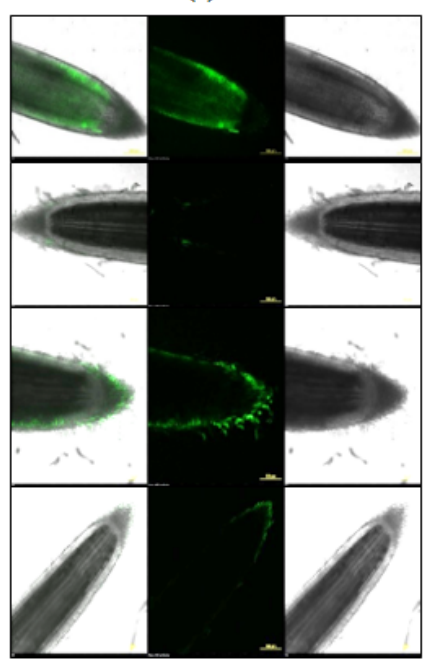

(d)

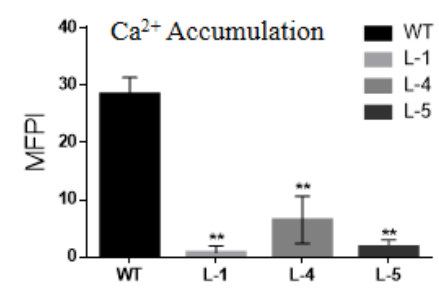

(e)

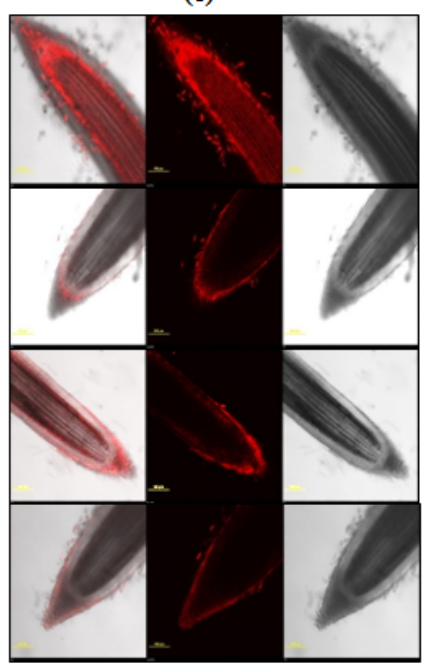

(f)

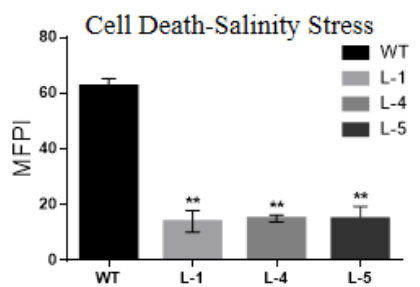

(g)

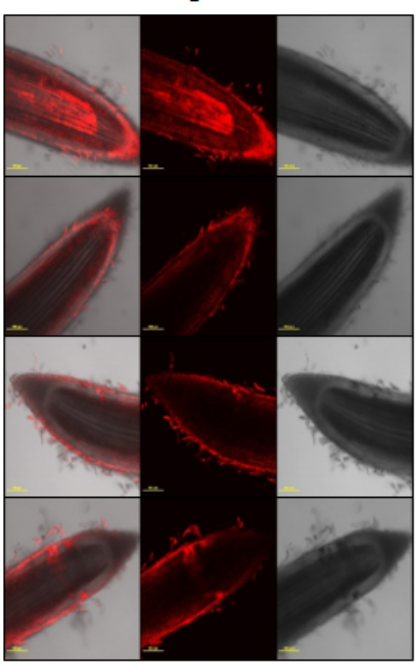

(h)

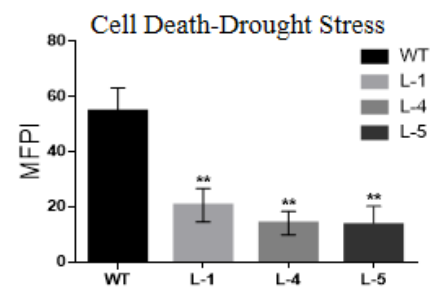

Figure 4

Biochemical analysis of OsRuvBL1a overexpressing transgenic lines for different time durations $(1,6,12$ and $24 \mathrm{hrs}$ ) (a-f) Under $200 \mathrm{mM} \mathrm{NaCl}$ concentration and (g-l) Under $150 \mathrm{mM}$ mannitol concentration (drought) showed stress tolerance in OsRuvBL1a transgenic lines for WT, L-1, L-4 and L-5 (a, g) Hydrogen peroxide content, $(b, h)$ Lipid peroxidation in terms of malondialdehyde (c, i) Proline content (d, j) Cell membrane stability in terms of percentage electrolyte retention (e, k) Enzymatic activity of Ascorbate peroxidase and $(f, l)$ Catalase. The significant difference between the mean values $(n=3)$ of WT and OsRuvBL1a overexpressing transgenic lines (L1, 4 and 5) were determined by two way analysis of variance (ANOVA) using Graphpad PRISM. The statistical significance was represented as “*” and "**” for $p<0.05$ and $p<0.01$ respectively. 
(a)

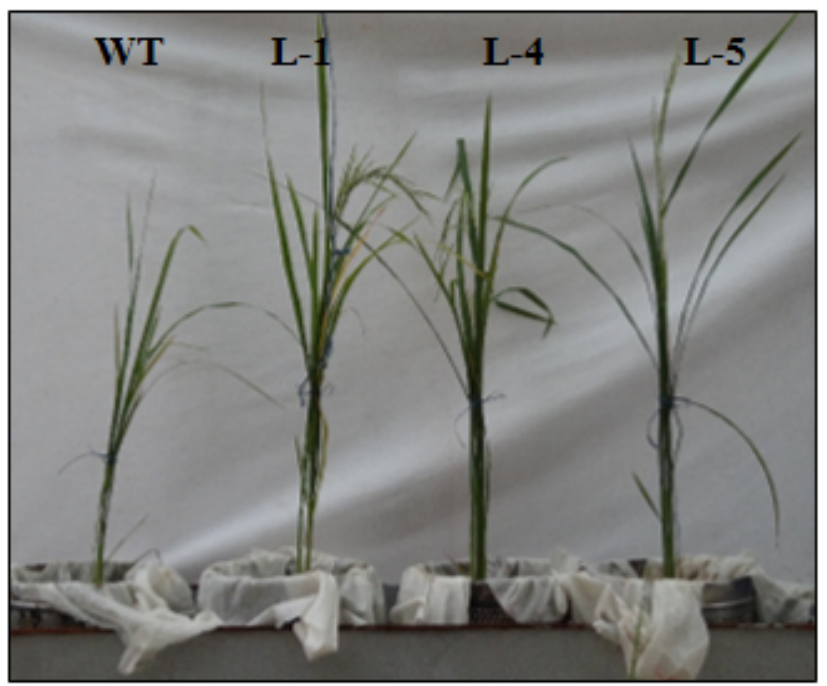

1 Day After Salinity Stress

(c)

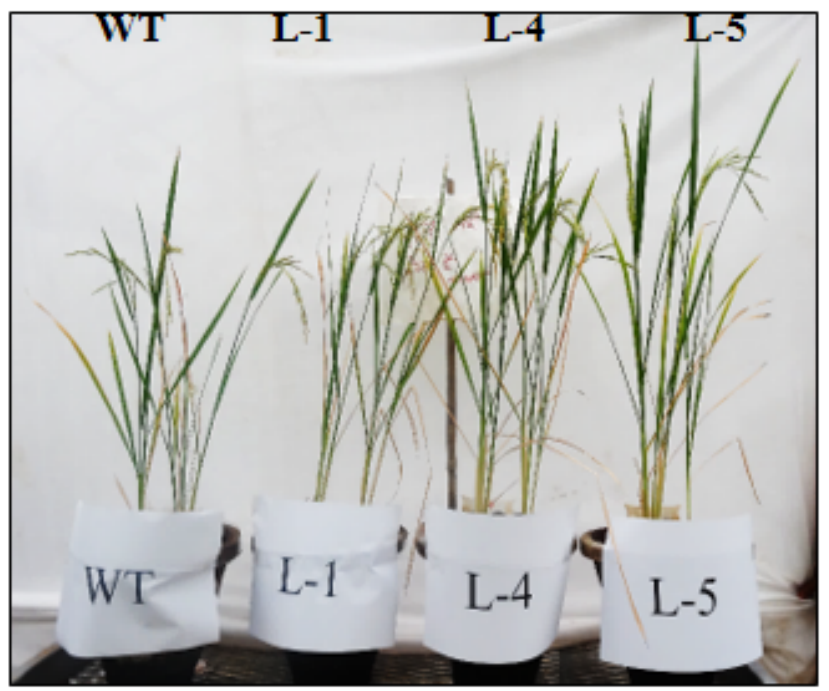

1 Day After Drought Stress (b)

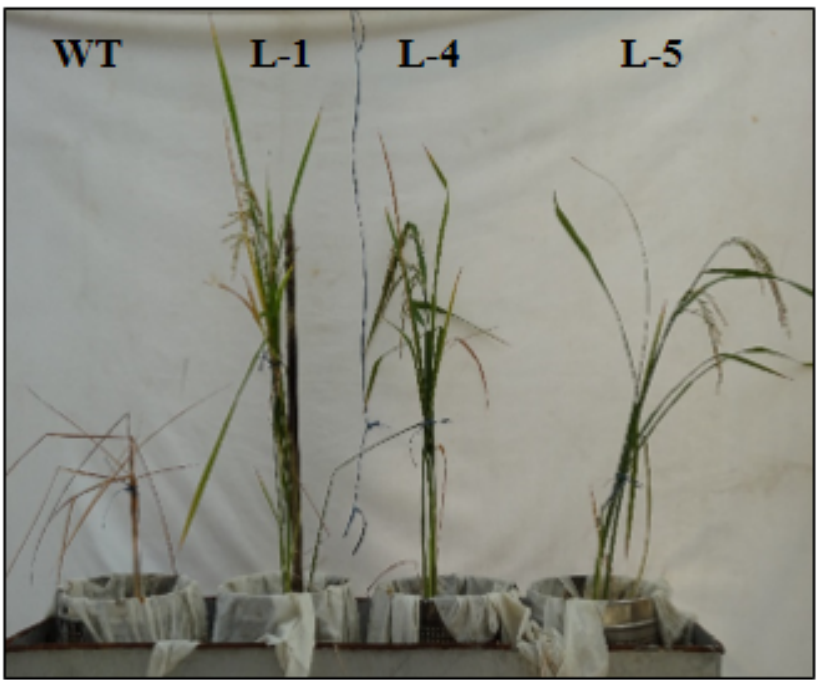

20 Days After Salinity Stress

(d)

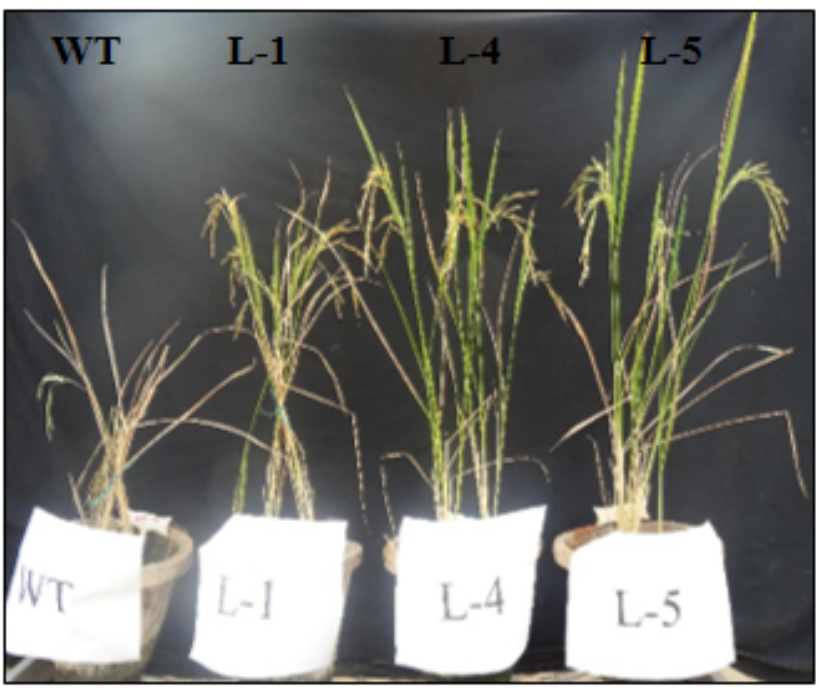

15 Days After Drought Stress

Figure 5

Confocal microscopy based analysis of roots (A, B) Na+ ion localization under $200 \mathrm{mM} \mathrm{NaCl}$ for $12 \mathrm{hrs}$. (C, D) Ca2+ ion localization under $200 \mathrm{mM} \mathrm{NaCl}$ for $12 \mathrm{hrs}$. (E, F) Cell viability analysis under $200 \mathrm{mM}$ $\mathrm{NaCl}$ for $12 \mathrm{hrs}$. $(\mathrm{G}, \mathrm{H})$ Cell viability analysis under $150 \mathrm{mM}$ mannitol for $12 \mathrm{hrs}$. The significant difference between the mean values $(n=3)$ of WT and OsRuvBL1a overexpressing transgenic lines $(L 1,4$ and 5$)$ were determined by two way analysis of variance (ANOVA) using Graphpad PRISM. The statistical significance was represented as " $\star$ " and "**" for $p<0.05$ and $p<0.01$ respectively. 


\section{Image not available with this version}

\section{Figure 6}

In vivo stress tolerance study $(a, b)$ Salinity and $(c, d)$ drought stress tolerance under in vivo conditions for same age plants $(a, c)$ Plants after salinity and drought stress Day 1 with WT and transgenic lines $(L-1,4$ and 5) where all plants are healthy. (b,d) Plants on 20th and 15th day after giving salinity and drought stress showing death of WT plant whereas OsRuvBL1a overexpressing transgenic line showed green tissue and survived the stress.

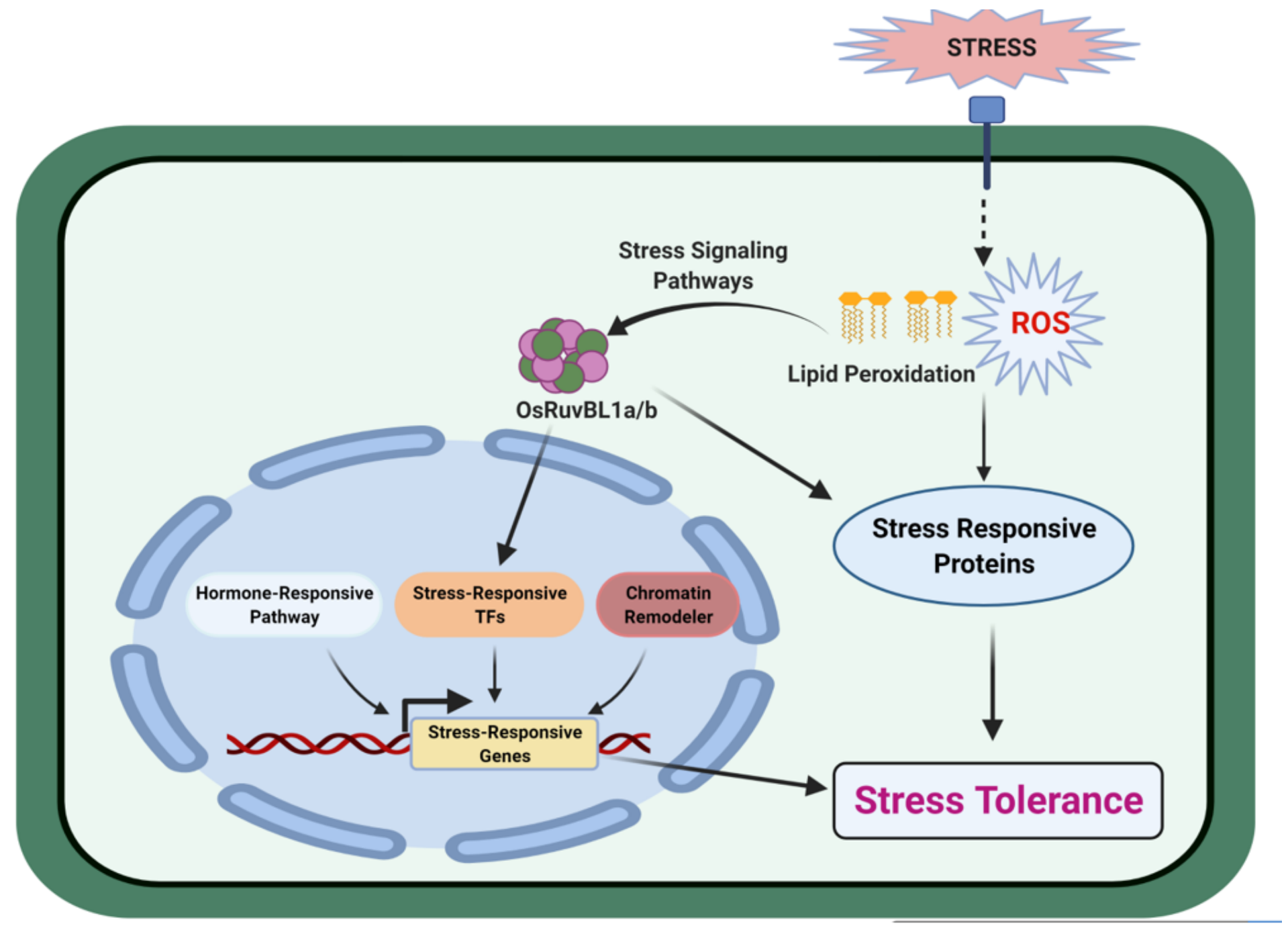


Figure 7

Hypothetical model for the working mechanism of OsRuvBL1a under stress condition.

\section{Supplementary Files}

This is a list of supplementary files associated with this preprint. Click to download.

- S.tables1840421.docx

- Sup1.png

- Sup2.png 